\title{
A Tough Reversible Biomimetic Transparent Adhesive Tape with Pressure-Sensitive and Wet-
}

Cleaning Properties

Ming $L i^{+}, *, a$, Weijun Li ${ }^{+}, *, b$, Qingwen Guan ${ }^{c}$, Xiaoli Dai ${ }^{d}$, Jing Lv ${ }^{*, e}$, Zhenhai Xia ${ }^{f}$, Wee-Jun Ong ${ }^{g}$, Eduardo Saiz ${ }^{a}$, Xu Hou ${ }^{b}$

a Centre of Advanced Structural Ceramics, Department of Materials, Imperial College London, London, SW7 2AZ, UK. Email: m.li19@imperial.ac.uk

${ }^{b}$ State Key Laboratory of Physical Chemistry of Solid Surfaces, College of Chemistry and Chemical Engineering, Xiamen University, Xiamen 361005, China. Email: 1wjdesky@163.com

c School of Chemistry, University of Glasgow, Glasgow, G12 8QQ, UK

${ }^{d}$ Environmental Protection Research Institute of Light Industry, Beijing 10089, China.

${ }^{\mathrm{e}}$ China University of Petroleum (Beijing), Beijing 102249, China. Email: 1vjing@,cup.edu.cn

${ }^{\mathrm{f}}$ Department of Materials Science and Engineering and Department of Chemistry, University of North Texas, Denton, Texas 76203, USA

g School of Energy and Chemical Engineering, Xiamen University Malaysia, Selangor Darul Ehsan 43900, Malaysia. College of Chemistry and Chemical Engineering, Xiamen University, Xiamen 361005, China

+ These two authors contribute equally to this work.

* Corresponding authors 
Table S1. The adhesion and microstructures of different bio-inspired dry adhesive surfaces

\begin{tabular}{|c|c|c|c|c|}
\hline Material & Fabrication method & $\begin{array}{l}\text { Characteristics of the microstructures } \\
\text { (structure, tip) }\end{array}$ & Performance (adhesion) & References \\
\hline PDMS & Casting & Vertical fibers, Mushroom-shaped tips & $\sim 219 \mathrm{kPa}$ & 1 \\
\hline PMMA & Hot embossing & Vertical fibers, Mushroom-shaped tips & $\sim 1.5 \mathrm{kPa}$ & 2 \\
\hline PDMS & Casting & Vertical fibers, Mushroom-shaped tips & $\sim 34.8 \mathrm{~N} \mathrm{~cm}^{-2}$ & 3 \\
\hline PDMS & Casting & Vertical fibers, Mushroom-shaped tips & $\sim 65 \mathrm{kPa}$ & 4 \\
\hline PU & Casting and dip coating & Hierarchical fibers, Mushroom-shaped tips & 6 times that of unstructured surface & 5 \\
\hline CNT and SU8 & $\begin{array}{l}\text { Photolithography, coating } \\
\text { and imprinting }\end{array}$ & Vertical carbon nanotube forests & $185 \pm 50 \mathrm{~N} \mathrm{~cm}^{-2}$ & 6 \\
\hline PDMS & Casting & $\begin{array}{l}\text { Three levels of hierarchy, Mushroom-shaped } \\
\text { fibers }\end{array}$ & $43.58 \pm 4.25 \mathrm{kPa}$ & 7 \\
\hline PDMS & Casting and bonding & $\begin{array}{l}\text { Two levels of hierarchy with thin film, } \\
\text { Mushroom-shaped fibers }\end{array}$ & $\sim 20 \mathrm{kPa}$ & 8 \\
\hline PDMS & Casting & Slanted fibers & $\begin{array}{l}\sim 8.4 \mathrm{~N} \mathrm{~cm}^{-2} \text { (friction in gripping } \\
\text { direction) }\end{array}$ & 9 \\
\hline $\begin{array}{l}\text { PUA and } \\
\text { nanoparticles }\end{array}$ & $\begin{array}{l}\text { Casting with magnetic field } \\
\text { gradient }\end{array}$ & Slanted fibers with gradient material & $\sim 9 \mathrm{~N} \mathrm{~cm}^{-2}$ & 10 \\
\hline PDMS & Casting & Wedged fibers & $5.1 \mathrm{kPa}$ & 11 \\
\hline PDMS & Casting & Wedged structures & $\sim 10.5 \mathrm{kPa}$ & 12 \\
\hline PUA & Casting & Nanohairs, Angled tips & $\sim 26 \mathrm{~N} \mathrm{~cm}^{-2}$ & 13 \\
\hline $\mathrm{PU}$ & Casting and dip coating & Slanted fibers, Angled spatula-shaped tips & $\sim 100 \mathrm{kPa}$ & 14 \\
\hline PU & Casting & Slanted fibers & $\sim 1.25 \mathrm{~N} \mathrm{~cm}^{-2}$ & 15 \\
\hline PU & Breath figure method & Micro porous & $\sim 120 \mathrm{kPa}$ & This work \\
\hline
\end{tabular}


Table S2. Cytotoxicity test results of glioma cells extraction in each group

\begin{tabular}{cccccc}
\hline Group & $\begin{array}{c}\text { Values of } \\
\text { absorption } \\
\text { at } 570 \mathrm{~nm}\end{array}$ & $\begin{array}{c}\text { Values of } \\
\text { absorption } \\
\text { at } 630 \mathrm{~nm}\end{array}$ & $\begin{array}{c}\text { Difference } \\
\text { of } \\
\text { absorption } \\
\text { between } \\
570 \mathrm{~nm} \\
\text { and } 630 \mathrm{~nm}\end{array}$ & $\begin{array}{c}\text { Relative } \\
\text { growth } \\
\text { rate (\%) }\end{array}$ & $\begin{array}{c}\text { Cytotoxicity } \\
\text { grade }\end{array}$ \\
\hline $\begin{array}{c}\text { Blank } \\
\text { control }\end{array}$ & $0.906 \pm 0.032$ & $0.218 \pm 0.012$ & $0.688 \pm 0.022$ & 100 & 0 \\
Negative \\
control
\end{tabular}

\section{Supplementary explanation}

\section{Cytotoxicity test:}

Sample: glioma cells

Preparation of different extracts.

Leaching solution group: Under aseptic conditions, a sample surface area of $15 \mathrm{~cm}^{2}$ was used. Cell culture medium was added and $5 \mathrm{~mL}$ of glioma cells $15 \%$ by volume were added. The sample was then incubated for $24 \mathrm{~h}$ at $37^{\circ} \mathrm{C}$.

$50 \%$ extracting solution group: The sample extract was diluted 1 time.

Negative control group: High-density polyethylene with a surface area of $30 \mathrm{~cm}^{2}$ was used. $5.0 \mathrm{~mL}$ of cell culture solution was added and the sample was incubated at $37^{\circ} \mathrm{C}$ for $24 \mathrm{~h}$.

Positive control group: $5.0 \mathrm{~mL}$ of cell culture medium containing $5 \mathrm{~g} / \mathrm{L}$ phenol was used and incubated at $37^{\circ} \mathrm{C}$ for $24 \mathrm{~h}$.

Blank control group: $5.0 \mathrm{~mL}$ of cell culture medium was used and incubated at $37{ }^{\circ} \mathrm{C}$ for $24 \mathrm{~h}$. 
Preparation of cell suspension: The normal subcultured glioma cells were digested with digestive juice to prepare a cell suspension with a concentration of $1 \times 10^{7} \mathrm{~L}^{-1}$, and seeded on a 96-well plate, with $100 \mu \mathrm{L} /$ well and 6 wells per group. The suspension was cultured in a $\mathrm{CO}_{2}$ incubator $\left(37^{\circ} \mathrm{C}\right.$, volume fraction of $5 \% \mathrm{CO}_{2}$ ).

Extraction of the extract: After the cells were cultured for $24 \mathrm{~h}$, the original cell culture solution was discarded, and the test sample group was exchanged with the extract solution and the $50 \%$ extract solution respectively; the blank control group, the negative control group and the positive control group were used for the corresponding control. The liquid was exchanged and exchanged in a $\mathrm{CO}_{2}$ incubator.

Determination of absorbance and cytotoxicity: $20 \mu \mathrm{L}$ of $5 \mathrm{~g} / \mathrm{L}$ tetramethylazozolium salt solution was added to each well to continue the culture after $72 \mathrm{~h}$ of culture time. After $4 \mathrm{~h}$, the liquid in the well was discarded and $150 \mu \mathrm{L}$ of dimethyl was added. Then sulfone was shaken on a shaker for $10 \mathrm{~min}$, and the absorbance at $570 \mathrm{~nm}$ and $630 \mathrm{~nm}$ was measured with a microplate reader. The relative growth rate (RGR) of the cells was calculated by the following formula: $R G R=\left(A / A_{0}\right) \times 100 \%$, where $A$ is the difference between the absorbance at $570 \mathrm{~nm}$ and $630 \mathrm{~nm}$ in the sample group (leaching solution group, $50 \%$ extract solution group, negative control group, positive control group); $A_{0}$ is the difference between the absorbance at $570 \mathrm{~nm}$ and $630 \mathrm{~nm}$ in blank control group. According to the magnitude of the relative proliferation rate, the corresponding toxicity level was found, and the cytotoxic reaction was (Table S3).

Table S3. Cytotoxicity reaction grading table

\begin{tabular}{cc}
\hline Reaction grading & Relative proliferation rate (\%) \\
\hline Level 0 & $\geq 100$ \\
Level 1 & $80 \sim 99$ \\
Level 2 & $50 \sim 79$ \\
Level 3 & $30 \sim 49$ \\
Level 4 & $0 \sim 29$ \\
\hline
\end{tabular}




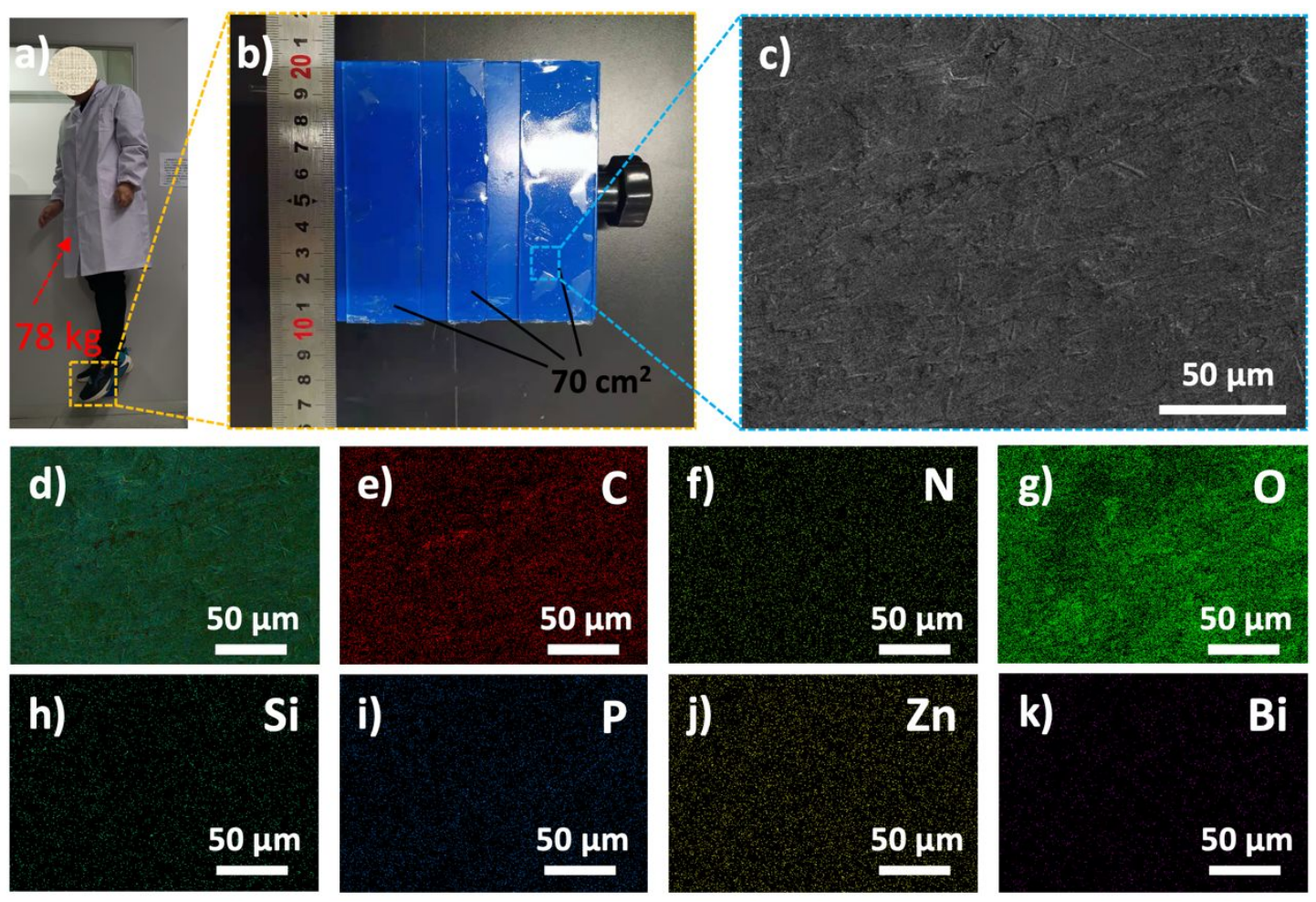

Figure S1. a) $78 \mathrm{~kg}$ in weight held by a steel surface with use of PU adhesive supported on the wall surface. b) The size of PU adhesive, $7 \mathrm{~cm}$ by $10 \mathrm{~cm}$. c) SEM image of PU adhesive. d) EDS layered image of PU adhesive. e-k) Distribution image of elements. e) C, f) $N, g$ ) $O, h$ ) Si, i) P, j) Zn, k) Bi. 
The electronic structure of -NCO:

$$
R-\ddot{N}=C=\ddot{O} \leftrightarrow R-\stackrel{\ominus}{\ddot{N}}-\stackrel{\oplus}{C}=\ddot{O} \leftrightarrow R-\ddot{N}=\stackrel{\oplus}{\stackrel{\oplus}{o ̈}:}
$$

The reaction process from isocyanate to polyurethane:

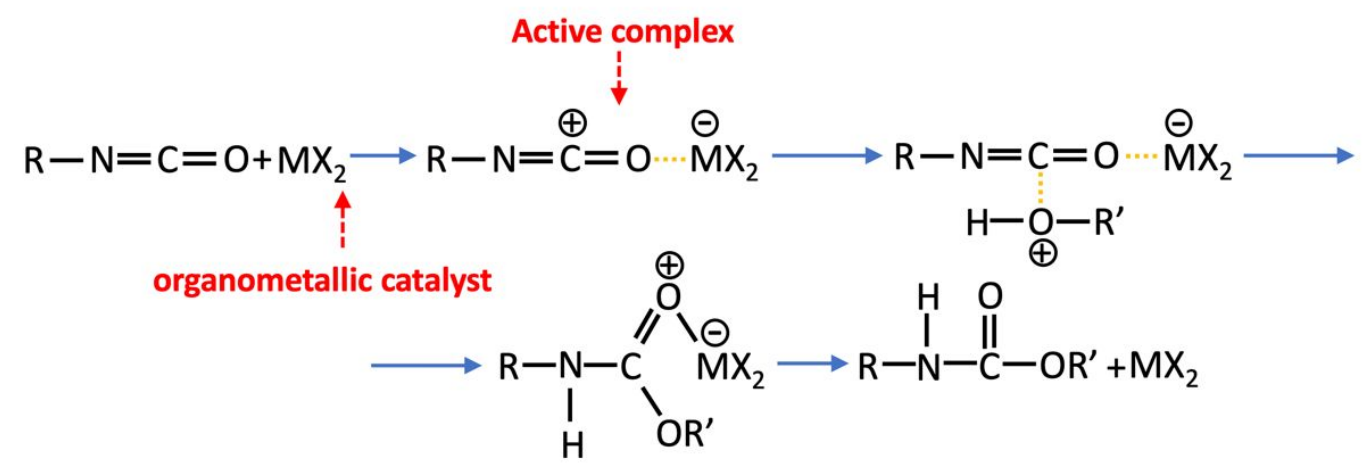

Figure S2. Schematic of the electronic structure of $-\mathrm{NCO}$ and the reaction process from isocyanate to polyurethane. 


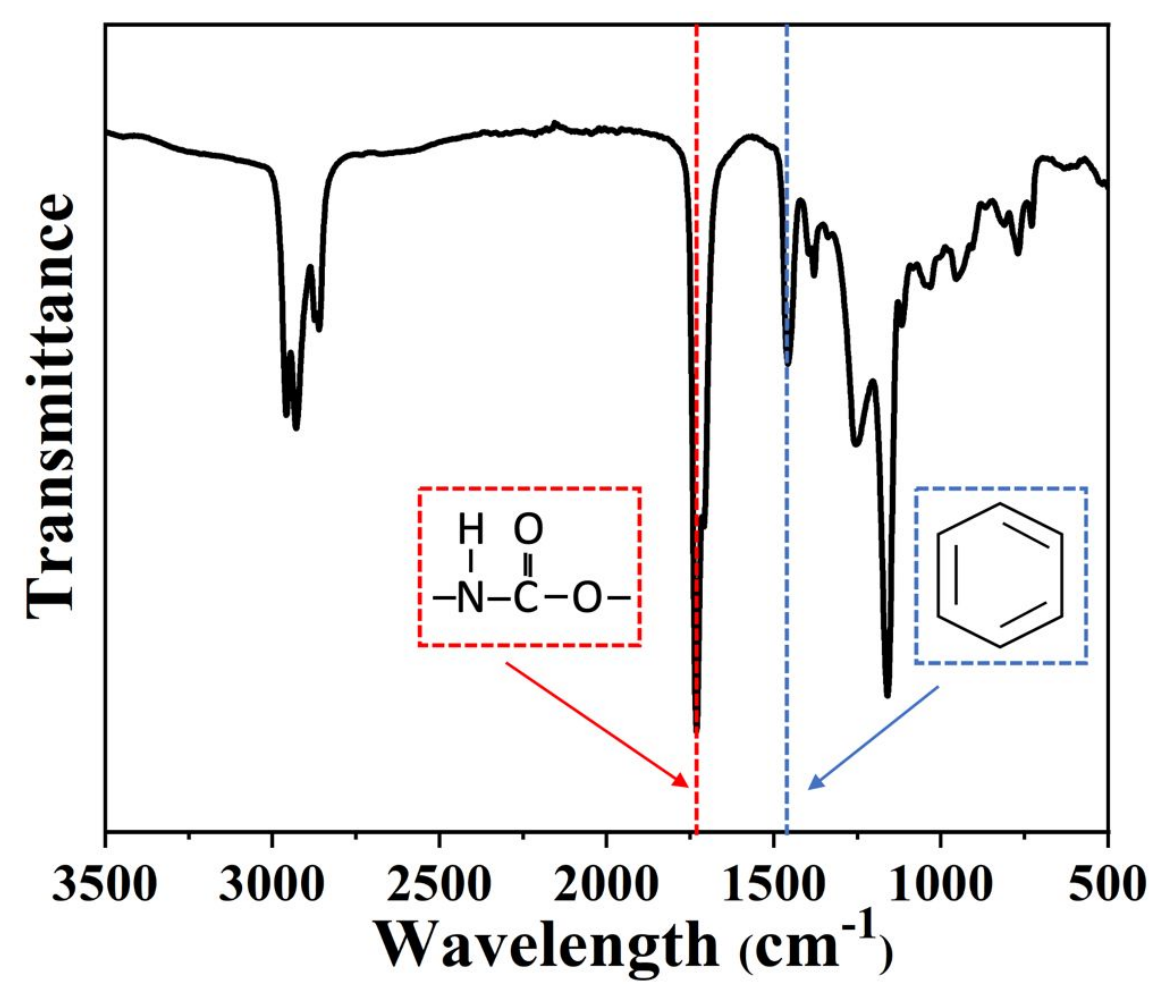

Figure S3. FTIR spectra of the polyurethane (PU) adhesive tape.

\section{Supplementary explanation}

On the one hand, the existence of the above structure enables the existence of reversible weak bonds in the adhesive network, such as $\pi-\pi$ conjugation, and hydrogen bonding. On the other hand, the N-H component in the polyurethane can form hydrogen bonds with the $\mathrm{N}, \mathrm{O}$ and $\mathrm{F}$ components on the solid surface, thereby improving adhesion. ${ }^{16,17}$ The $\mathrm{C}=\mathrm{O}$ component contained can not only form hydrogen bonds with $-\mathrm{OH}$ and $-\mathrm{NH}_{2}$ on the solid surface, but also form metal complexes with metal ions to enhance adhesion. ${ }^{18}$ Moreover, the polyurethane could exhibit hydrophobic interaction (hydrophobic molecule chain). ${ }^{19}$ In addition, polyurethane also contains unsaturated benzene ring structure, so there are $\pi-\pi$ stacking and cation- $\pi$ interaction. ${ }^{20}$ 

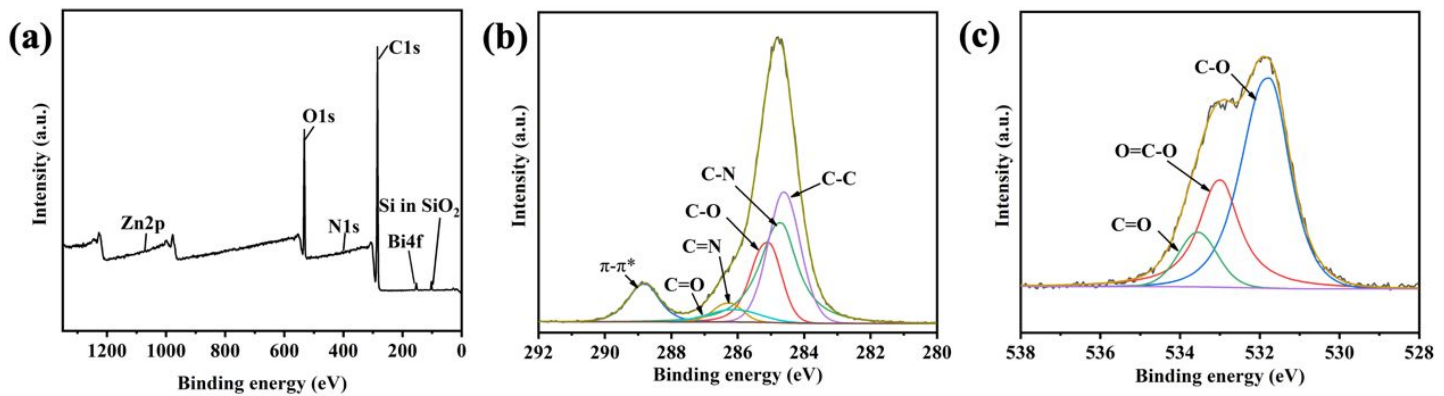

Figure S4. XPS spectra of the PU adhesive. a) XPS full-spectrum curves. b) the highmagnification XPS curves for C 1s. c) the high-magnification XPS curves for O 1s.

\section{Supplementary explanation}

The characteristic peaks of $\mathrm{C}, \mathrm{O}, \mathrm{Si}$ and Bi elements are found in Figure S4. The XPS high-resolution $\mathrm{C} 1 \mathrm{~s}$ curve of the PU adhesive is shown in Figure S4b that shows a $\mathrm{C}-\mathrm{N}$ bond at $284.73 \mathrm{eV}, \mathrm{C}-\mathrm{O}$ bond at $285.08 \mathrm{eV}, \mathrm{C}=\mathrm{N}$ bond at $286.18 \mathrm{eV}, \mathrm{C}=\mathrm{O}$ bond at $285.93 \mathrm{eV}$ and $\mathrm{a} \pi-\pi^{*}$ bond at $288.83 \mathrm{eV}$ on the curve belonging to the isocyanate groups, ether group, ester group and polyether polyols in the material, respectively. Similarly, the high-magnification XPS curve for O1s is given in Figure S4c that shows a $\mathrm{C}-\mathrm{O}$ bond at $531.83 \mathrm{eV}, \mathrm{O}=\mathrm{C}-\mathrm{O}$ bond at $533.03 \mathrm{eV}$ and $\mathrm{C}=\mathrm{O}$ bond at $533.58 \mathrm{eV}$. 

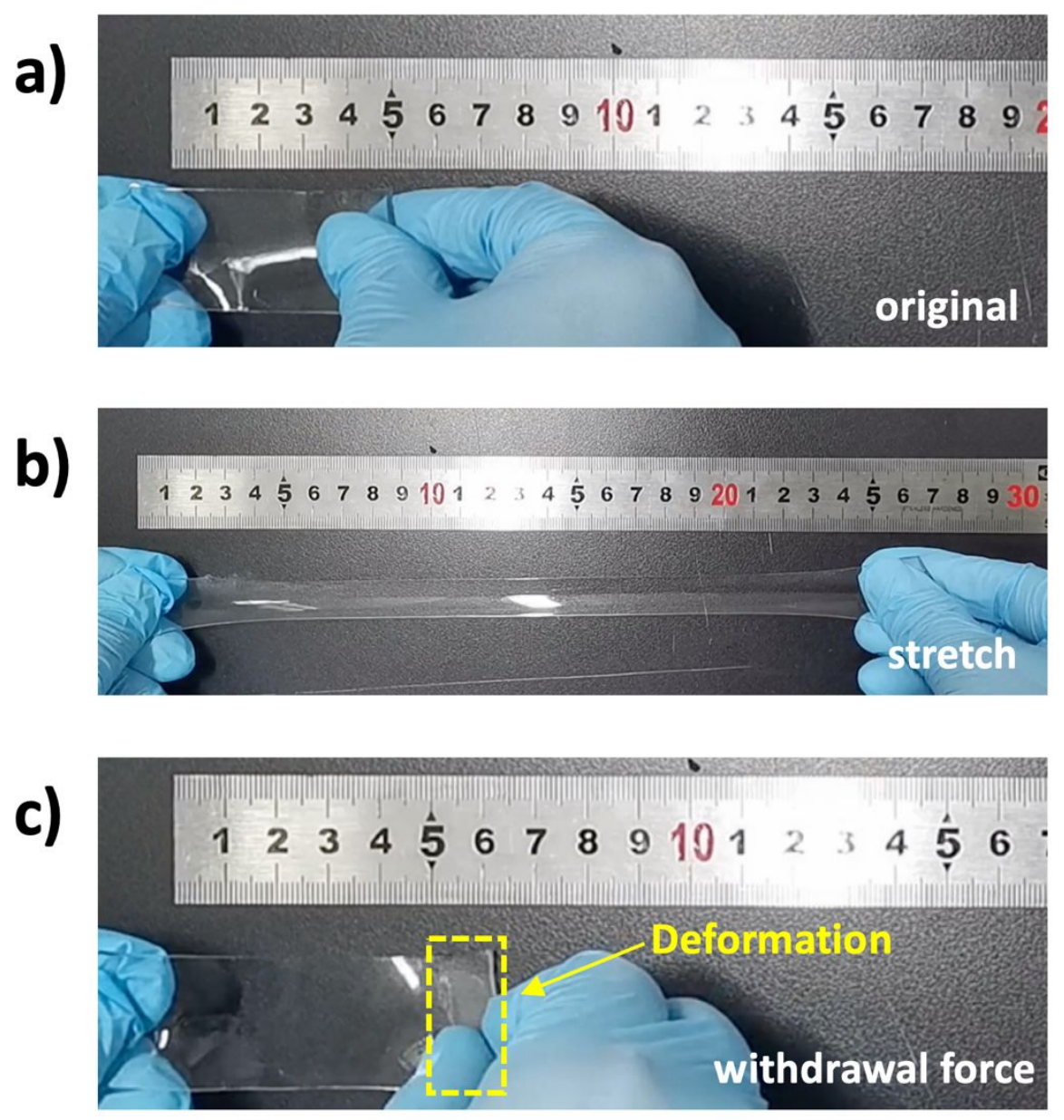

Figure S5. a) Photo of the initial PU adhesive. b) Photograph of the stretched PU adhesive. d) Photograph of the PU adhesive after stretching. 


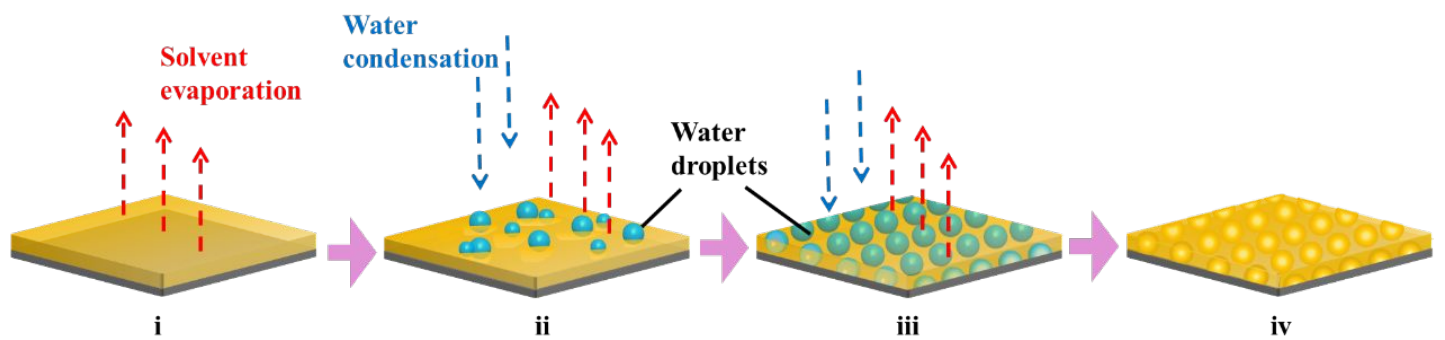

Figure S6. The mechanism of the formation of the microstructures on the PU surface. 


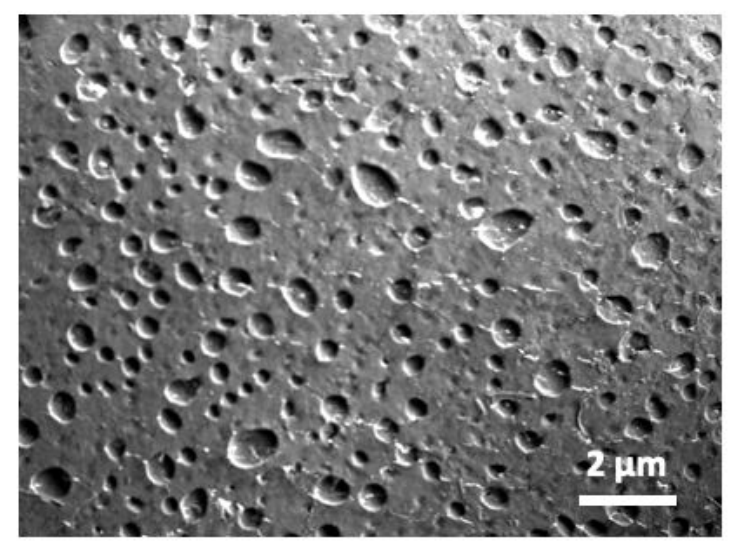

Figure S7. SEM image of the surface structure of the PU adhesive tape. 

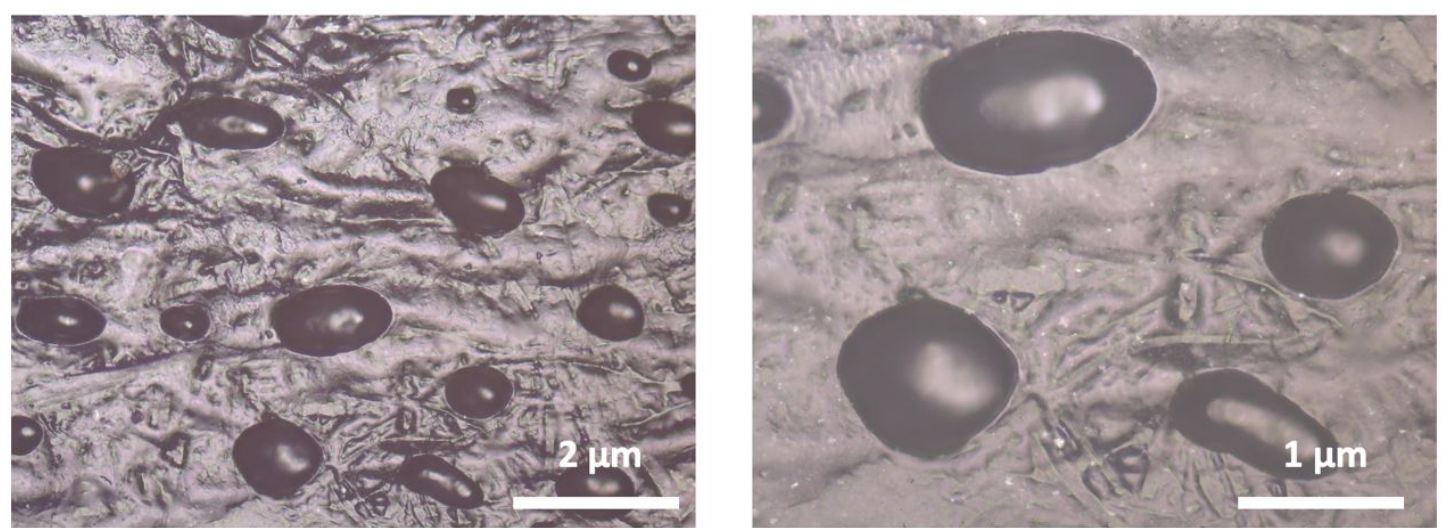

Figure S8. Photographs of the PU adhesive tape's surface under a high power optical microscope. 
a)

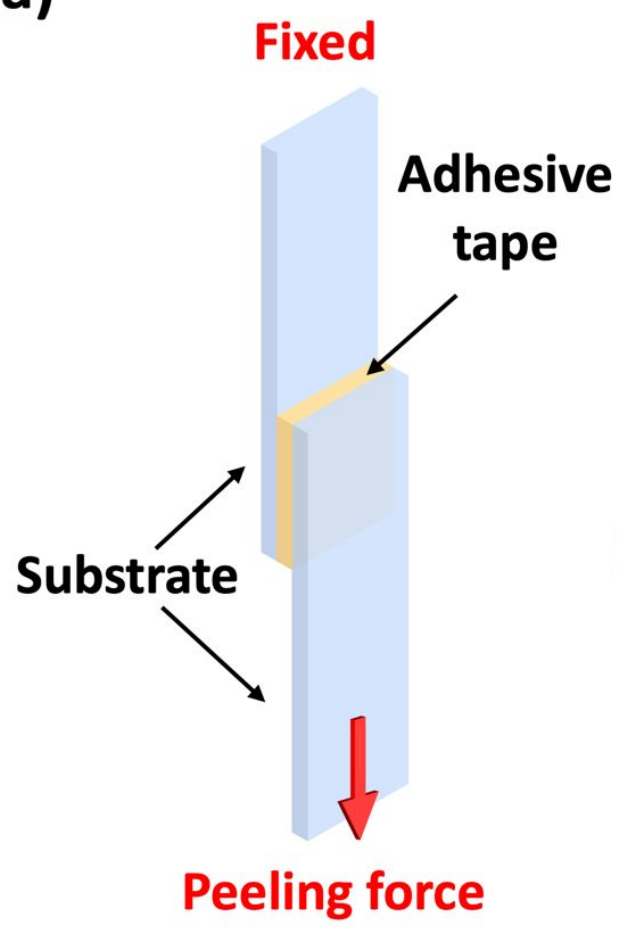

b)

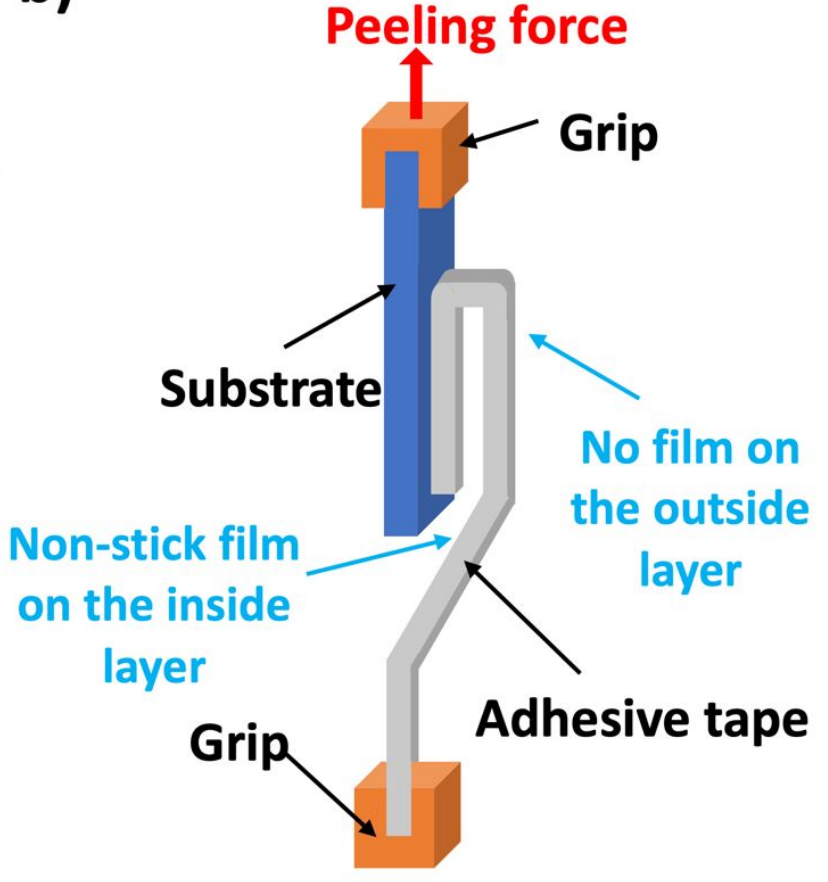

Fixed

Figure S9. a) Schematic illustration of the static adhesion strength test of the PU adhesive tape on the solid substrate. b) Schematic illustration of the $180^{\circ}$ peeling force test of the PU adhesive tape on the solid substrate. 

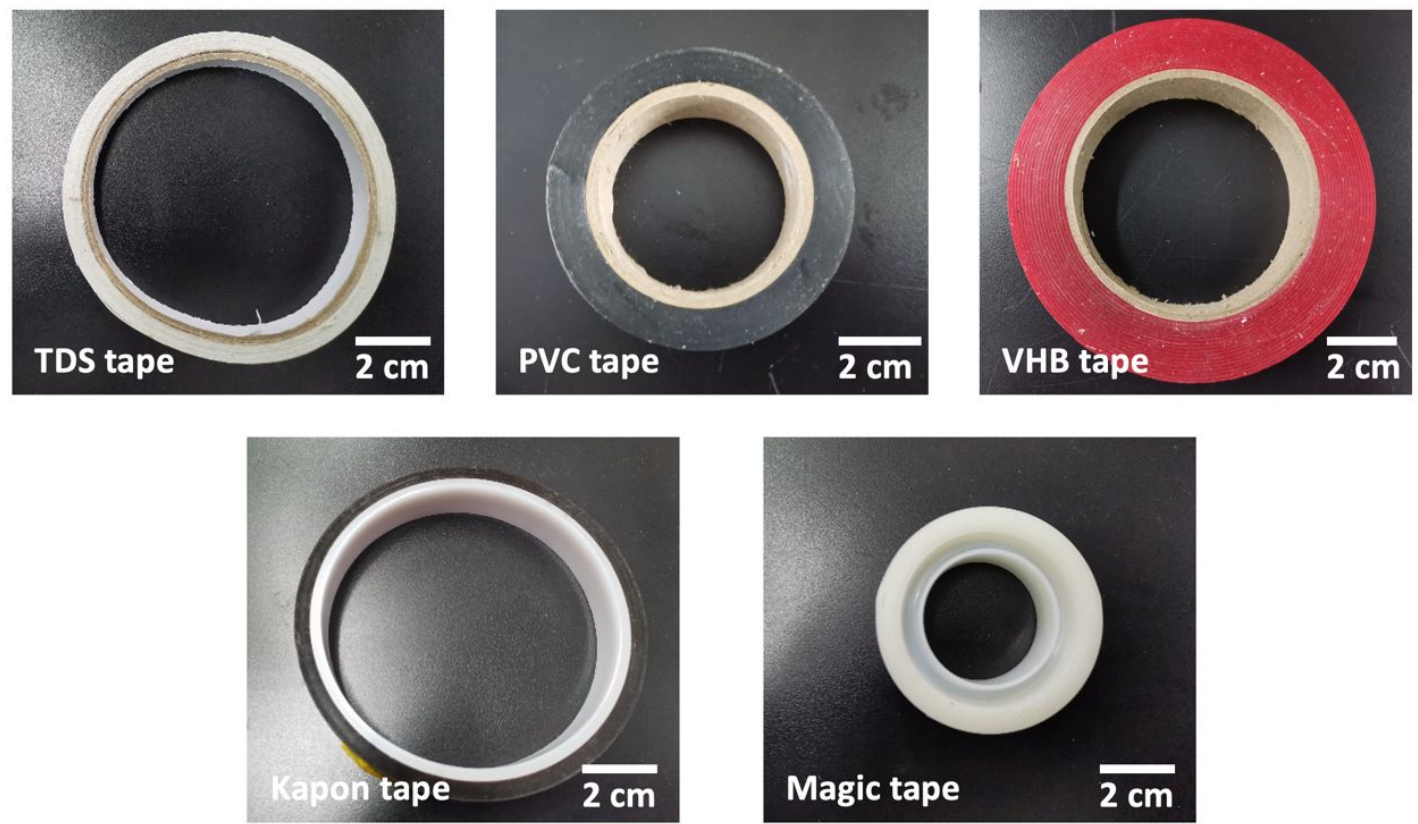

Figure S10. Different commercially available tapes, including traditional double-sided tape (TDS tape), PVC tape, 3M VHB tape, Kapton tape and 3M magic tape. 

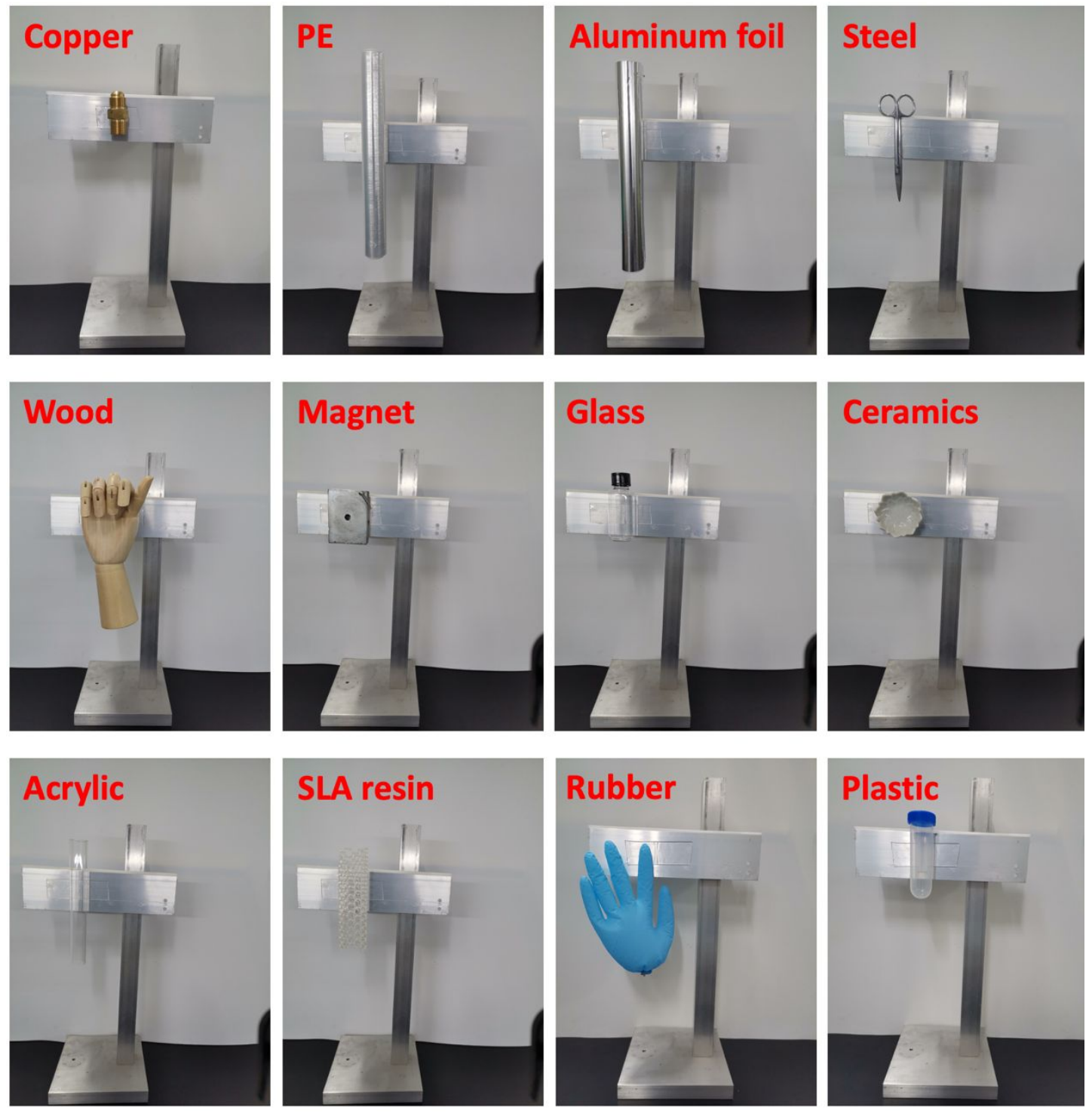

Figure S11. Adhesion between different adherends and PU adhesive, including copper, PE, aluminum foil, steel, wood, magnet, glass, ceramics, acrylic, SLA resin, rubber, and plastic (from left to right and then from top to bottom). 

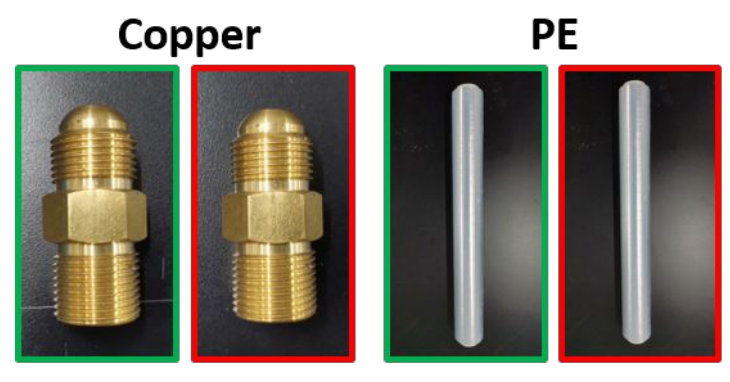

Aluminum foil
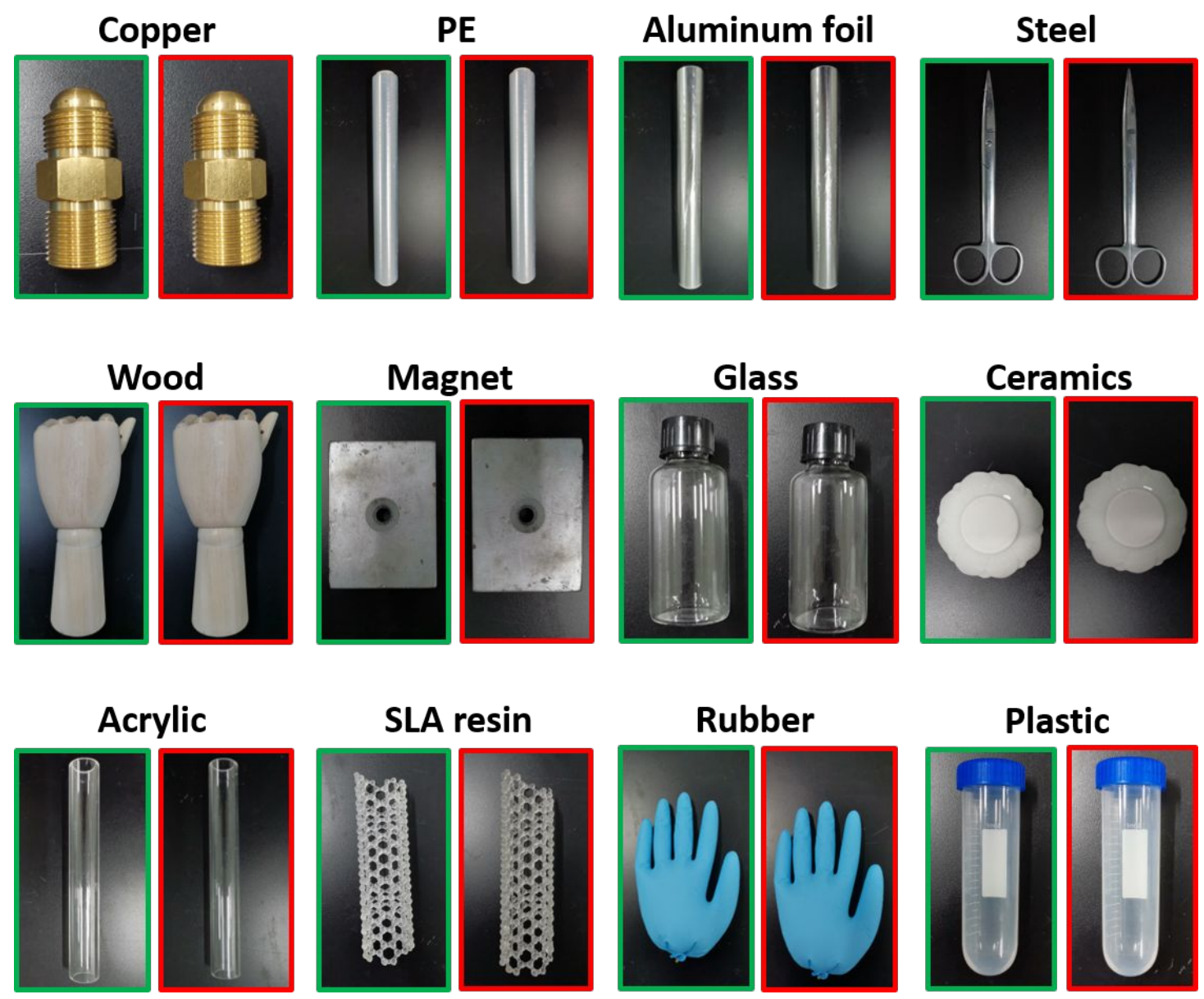

Figure S12. Photographs before and after adhesion for different adherends, including copper, PE, aluminum foil, steel, wood, magnet, glass, ceramics, acrylic, SLA resin, rubber, and plastic (the green ones are before adhesion, the red ones are after adhesion), which indicate no adhesive residue after peeling off. 

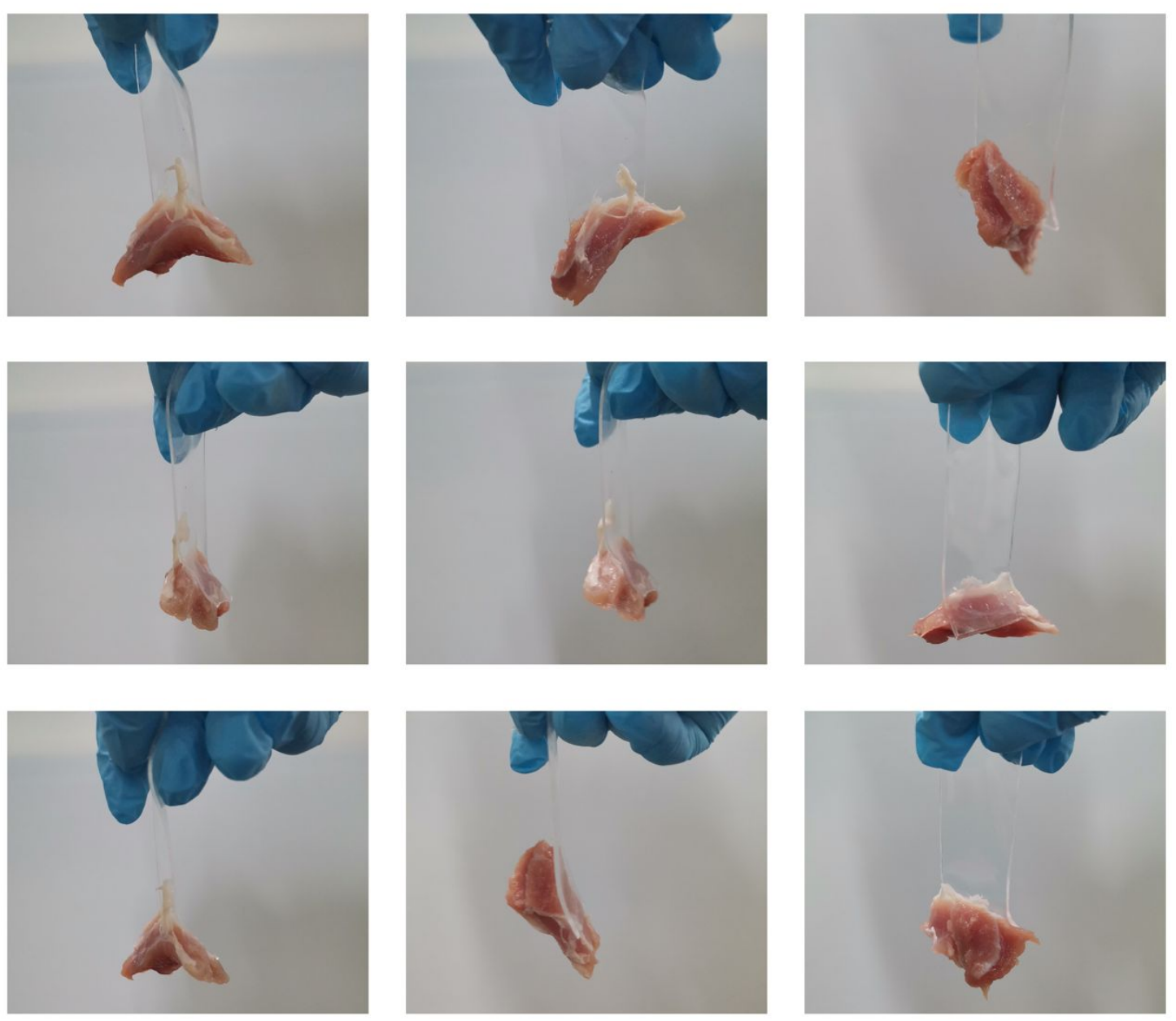

Figure S13. Photographs of PU adhesive adhering to biological tissue (different viewing angles). 

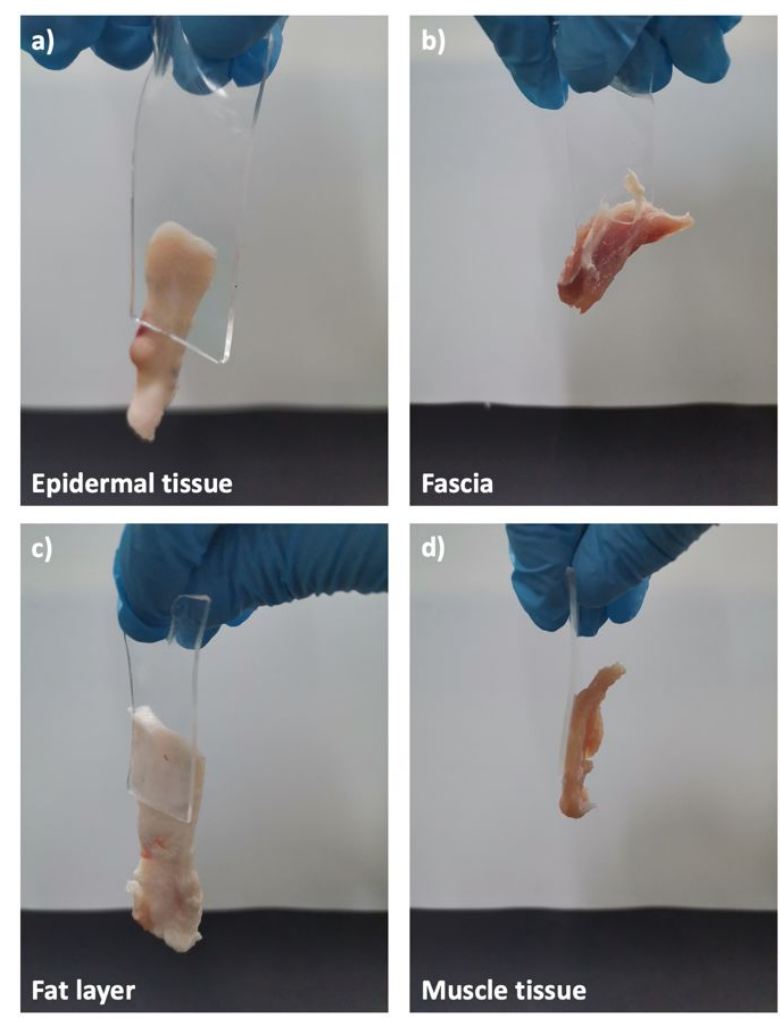

Figure S14. Photographs of PU adhesive adhering to different biological tissue structures. 

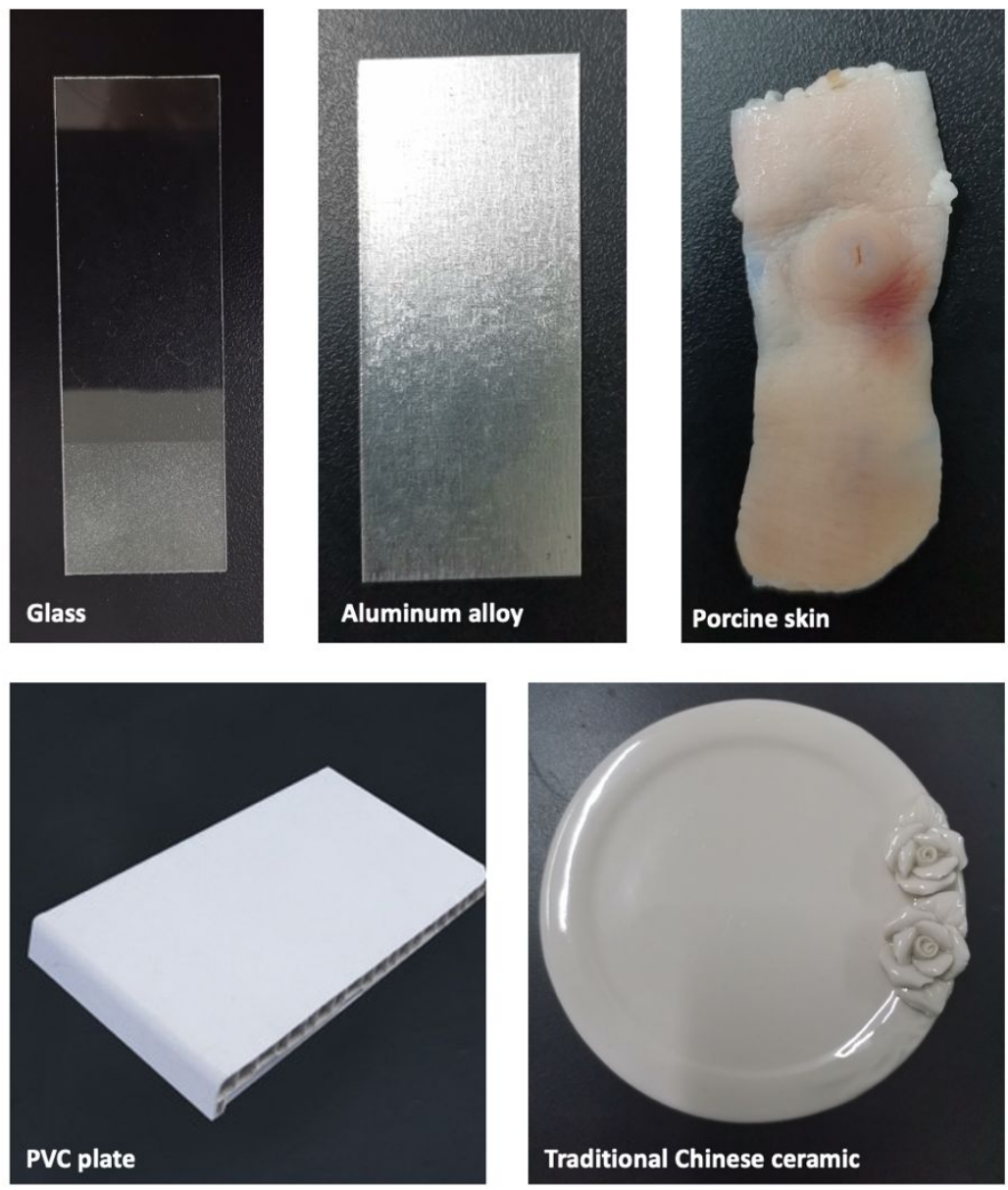

Figure S15. Different substrates, including glass, aluminum alloy, porcine skin, PVC plate and traditional Chinese ceramic. 


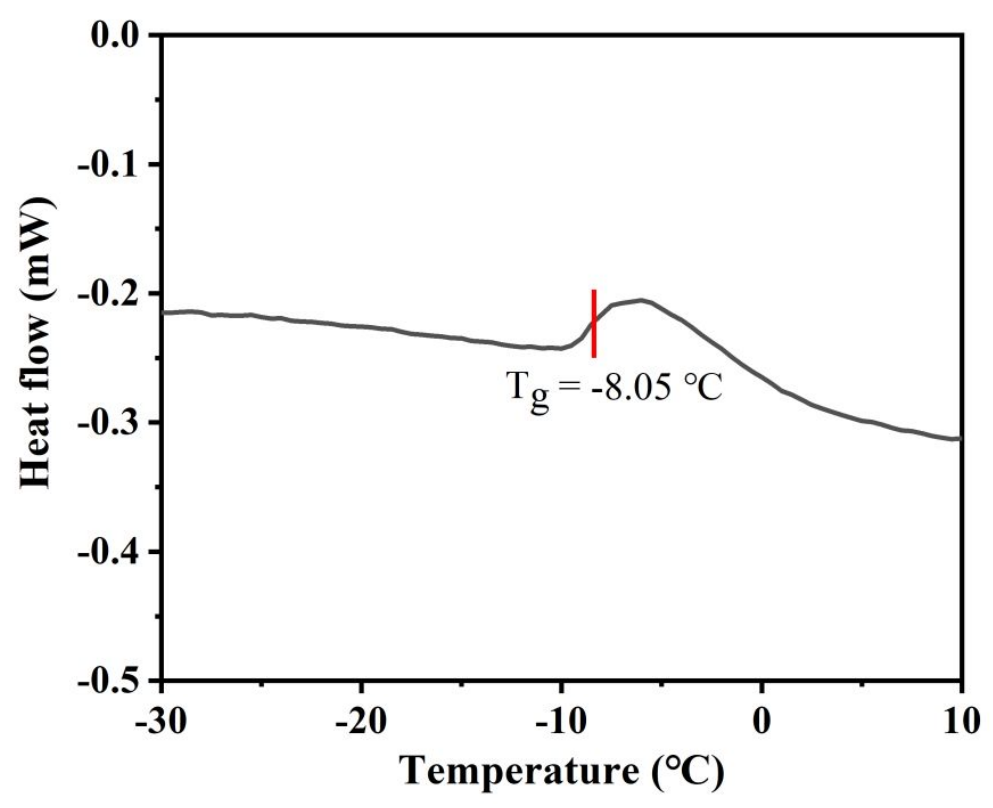

Figure S16. The glass transition temperatures (Tg) of the PU adhesive. 

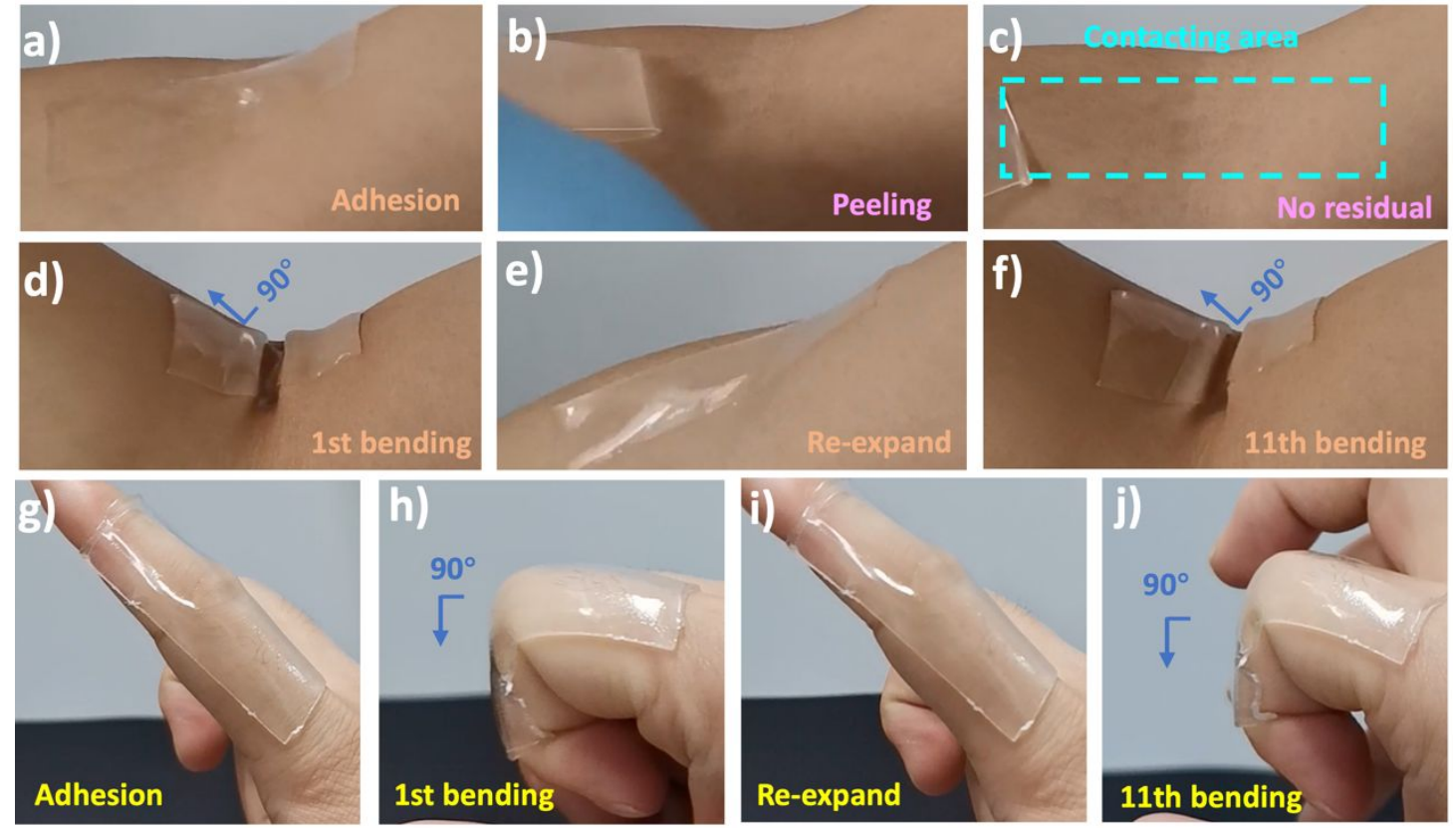

Figure S17. a-c) Photographs of adhesion and peeling behavior on the skin of arms. d-j) Dynamic adhesion behavior of PU adhesive: d-f) Retraction movement and g-j) stretching movement. 
a)

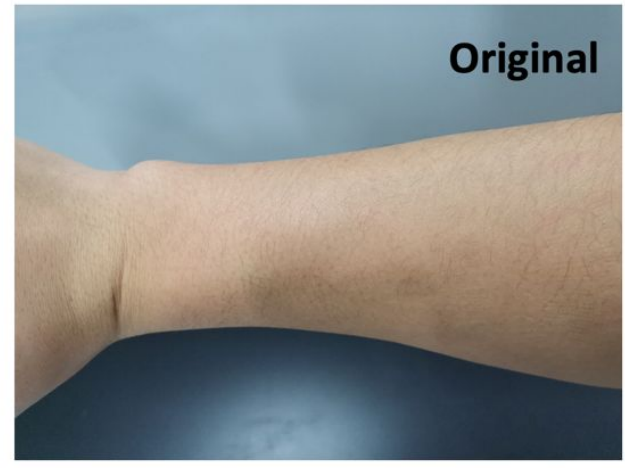

c)

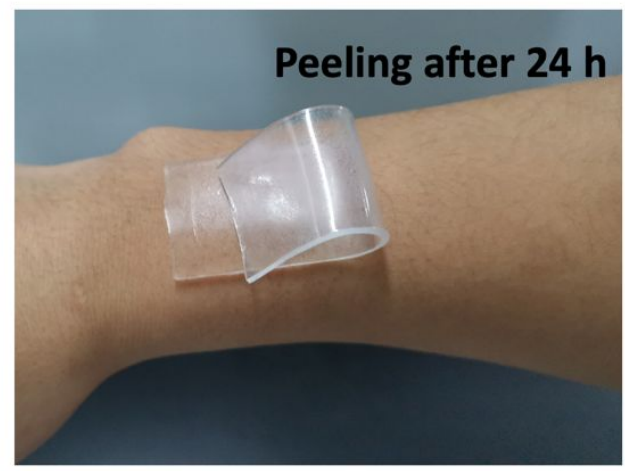

b)

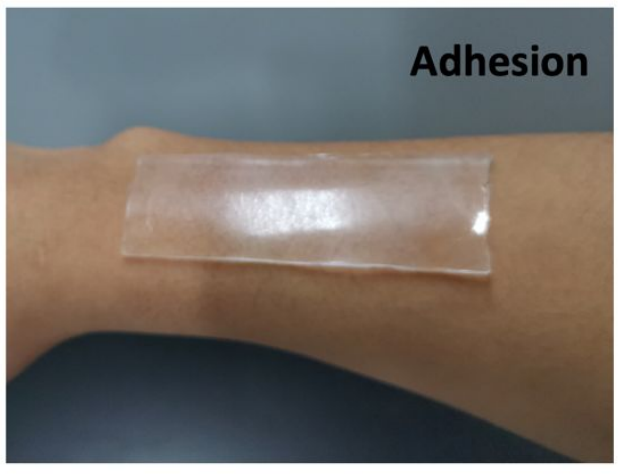

d)

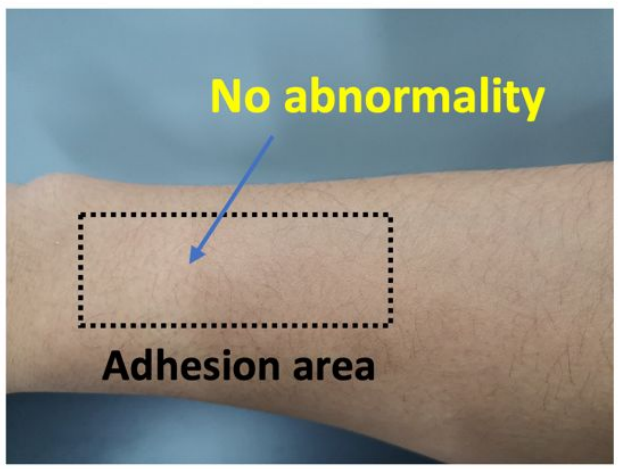

Figure S18. Photographs of the skin adhesion area before and after PU adhesive adhered for 24 hours. 

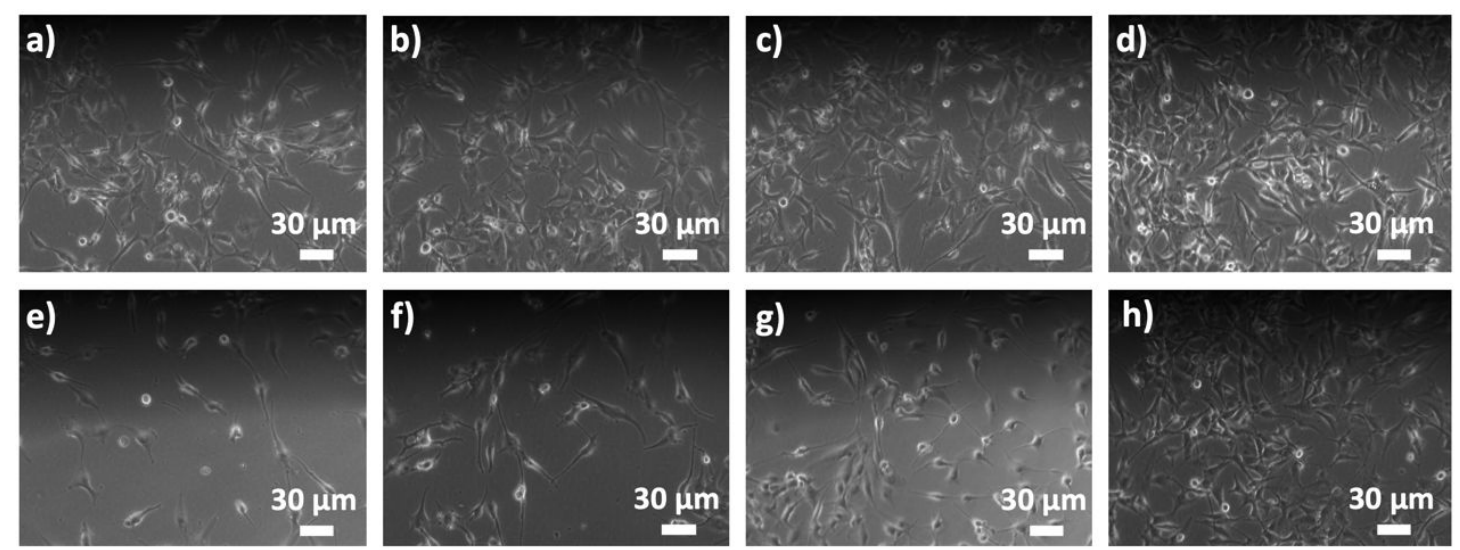

Figure S19. a) Image of glioma cells after adherent growth (blank control group). b) Image of glioma cells after one day of growth (blank control group). c) Image of glioma cells after two days of growth (blank control group). d) Image of glioma cells after three days of growth (blank control group). e) Image of glioma cells after adherent growth (testing group). f) Image of glioma cells after one day of growth (testing group). g) Image of glioma cells after two days of growth (testing group). h) Image of glioma cells after three days of growth (testing group). 

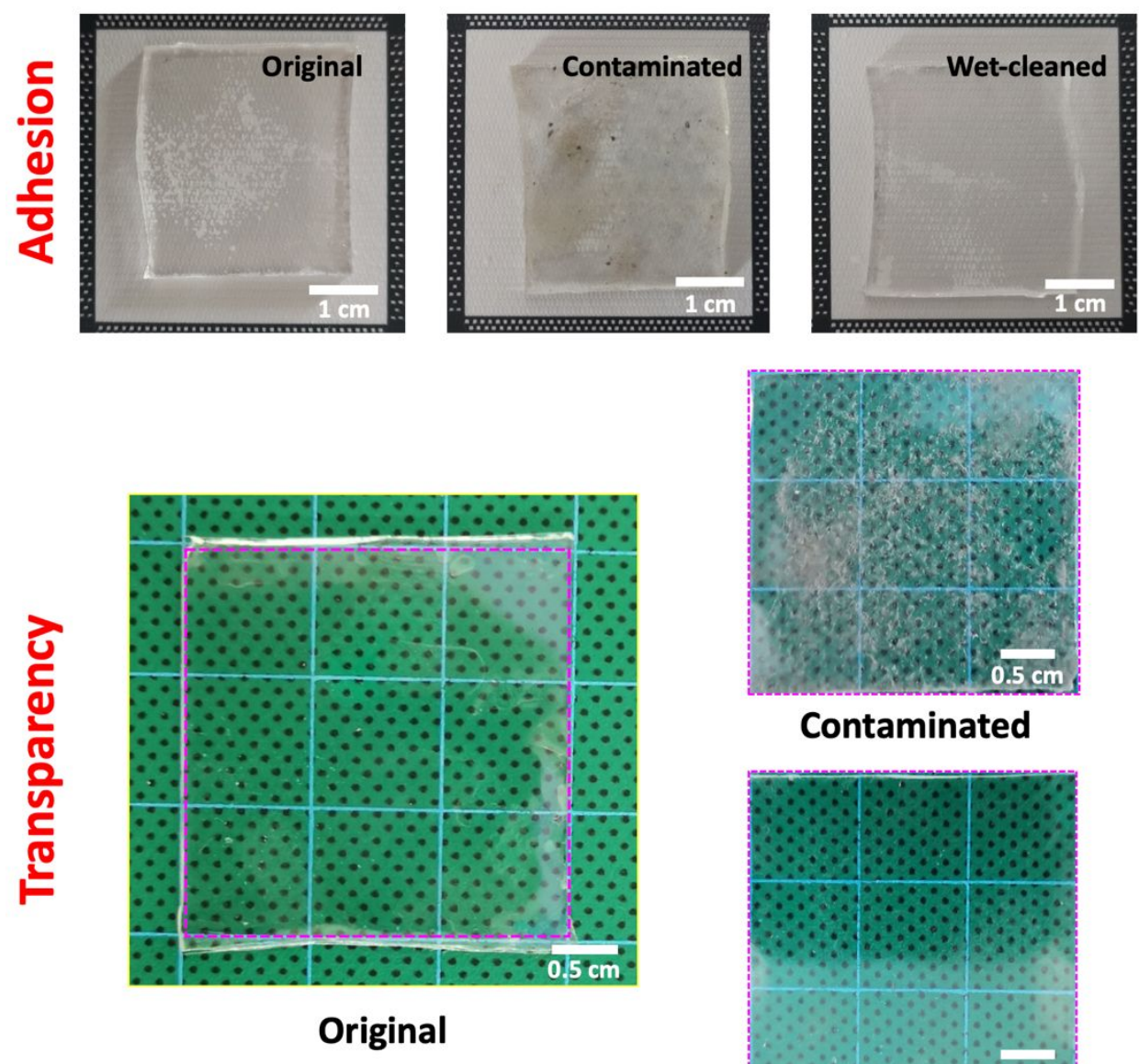

\section{Contaminated}

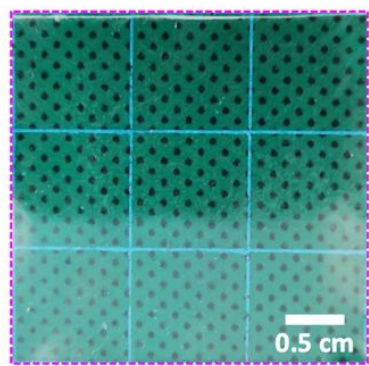

Wet-cleaned

Figure S20. Photographs of original, contaminated and wet-cleaned PU adhesive tape. 


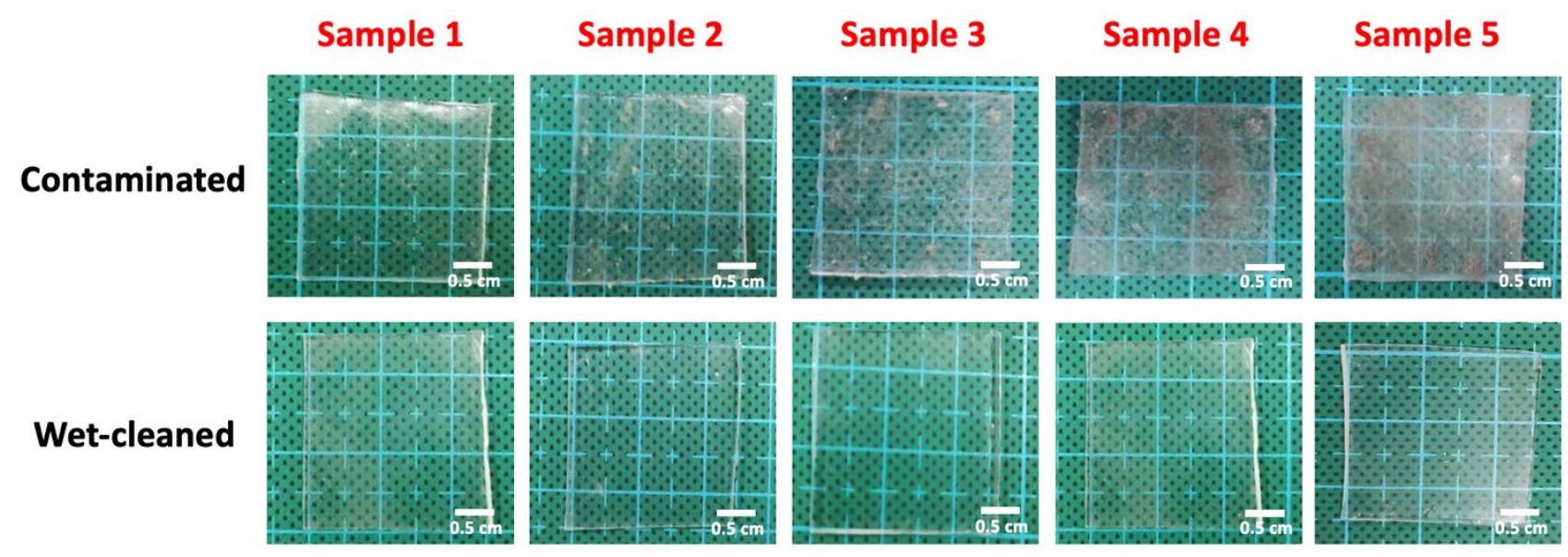

Figure S21. Five independent PU adhesives with different degrees of pollution before and after wetcleaning in Figure 3d. 

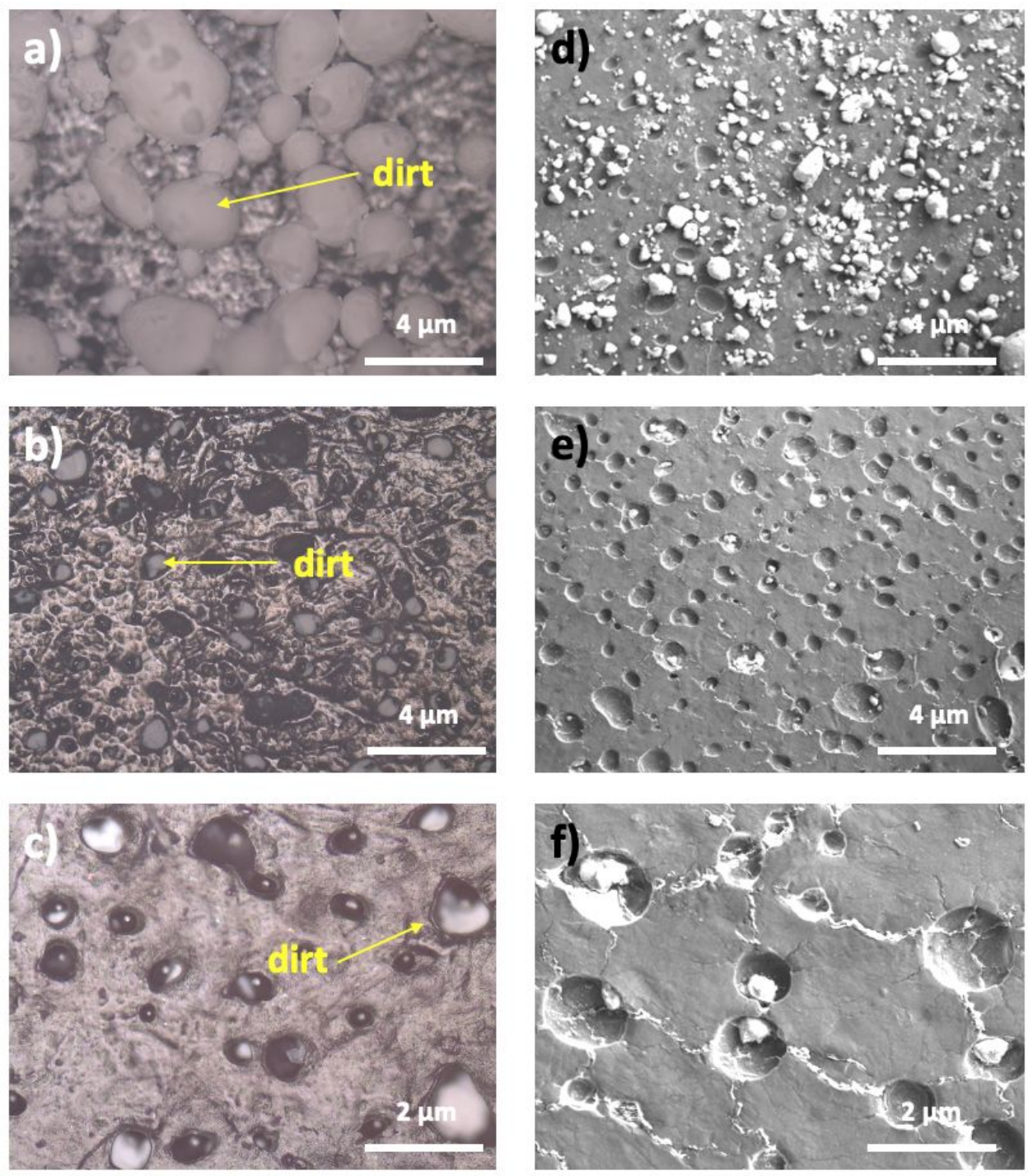

Figure S22. a-d) Optical images of the PU adhesive tape's surface: a) original, b) dirt contaminated, c,d) after wet-cleaning. e-h) SEM images of the surface of the PU adhesive: e) original, f) dirt contaminated, $g, h$ ) after wet-cleaning. 


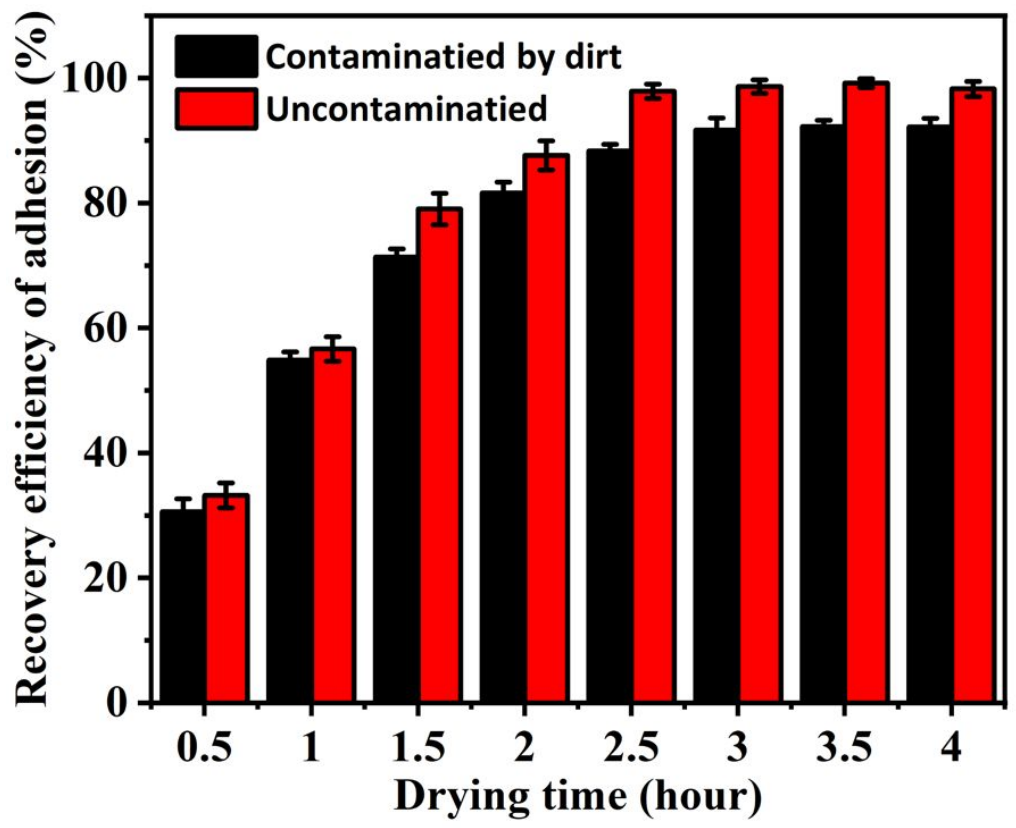

Figure S23. The adhesion recovery percentage of contaminated and uncontaminated PU adhesives changed with the drying time at a drying temperature of $30^{\circ} \mathrm{C}$ (Contamination: dirt) 

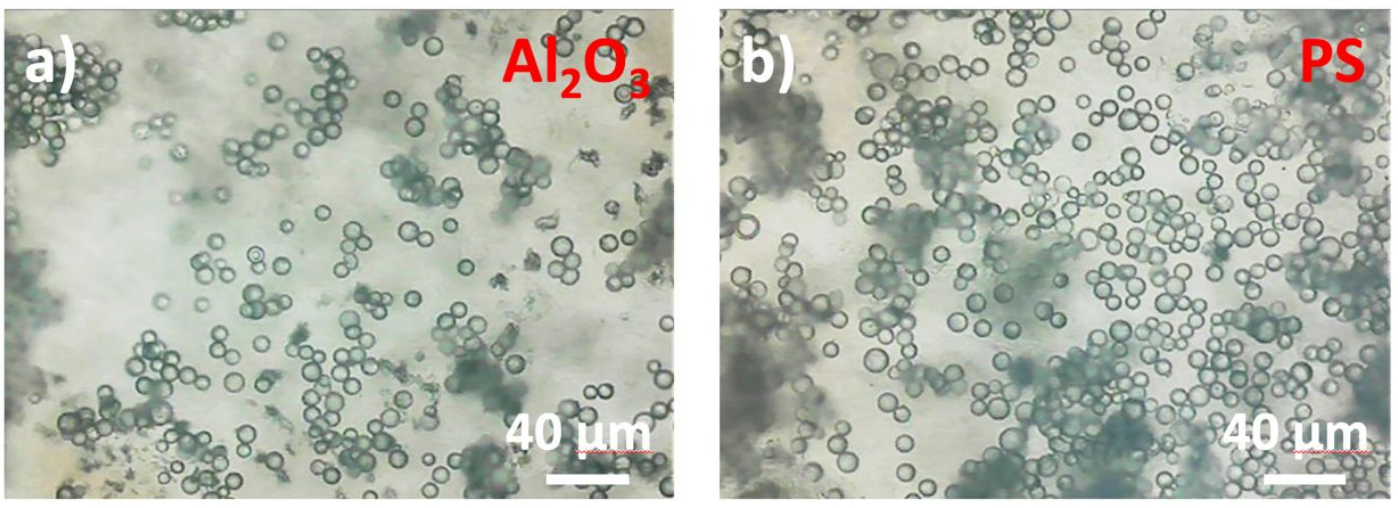

Figure S24. a) Photograph of $\mathrm{Al}_{2} \mathrm{O}_{3}$ balls $(1,5,8 \mu \mathrm{m})$ under a high power optical microscope. $\left.\mathrm{b}\right)$ Photograph of PS balls $(1,5,8 \mu \mathrm{m})$ under a high power optical microscope. 


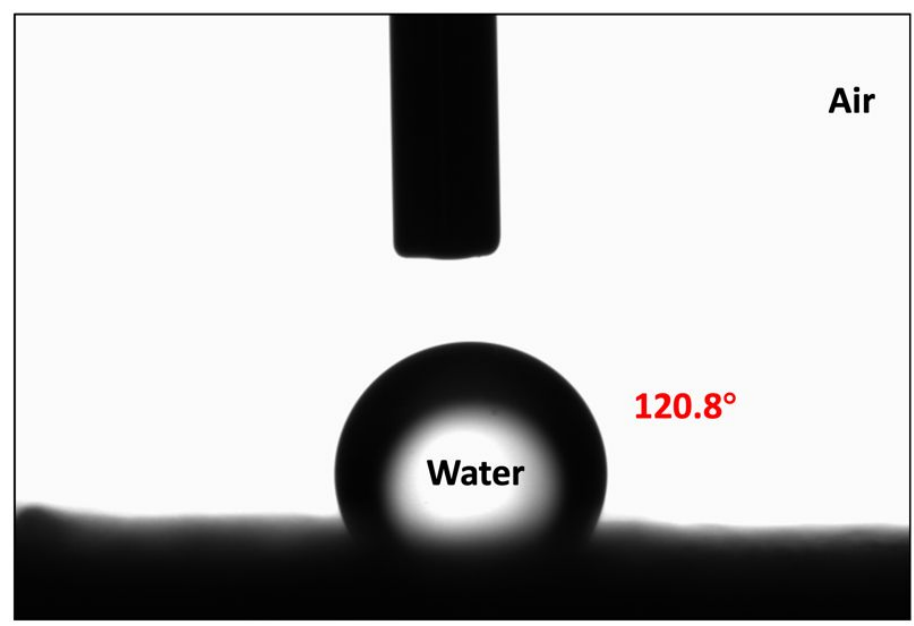

Figure S25. Contact angle between PU adhesive tape and water in air. The contact angle was $120.8^{\circ}$. 

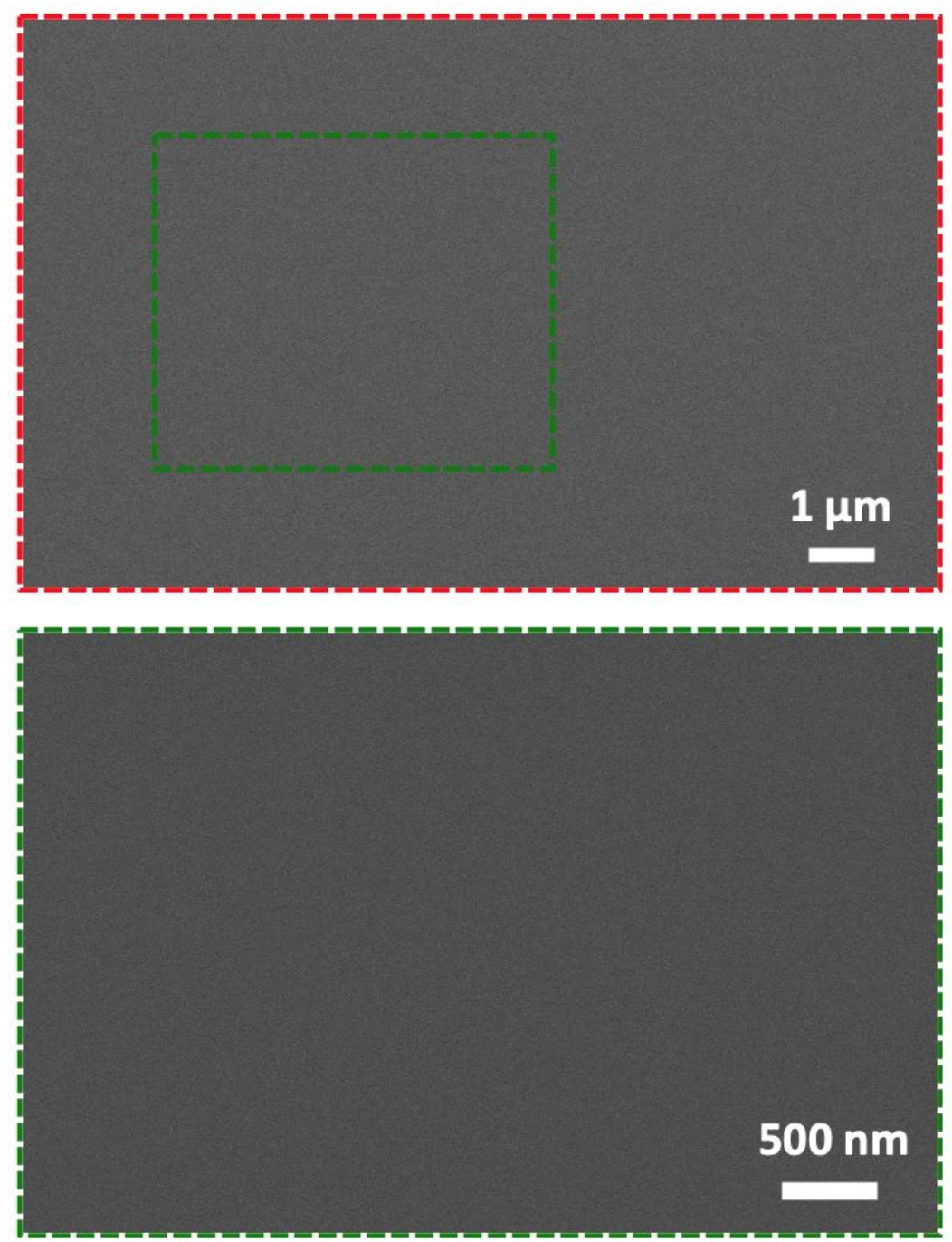

Figure S26. SEM image of the surface morphology of silicon wafer. 


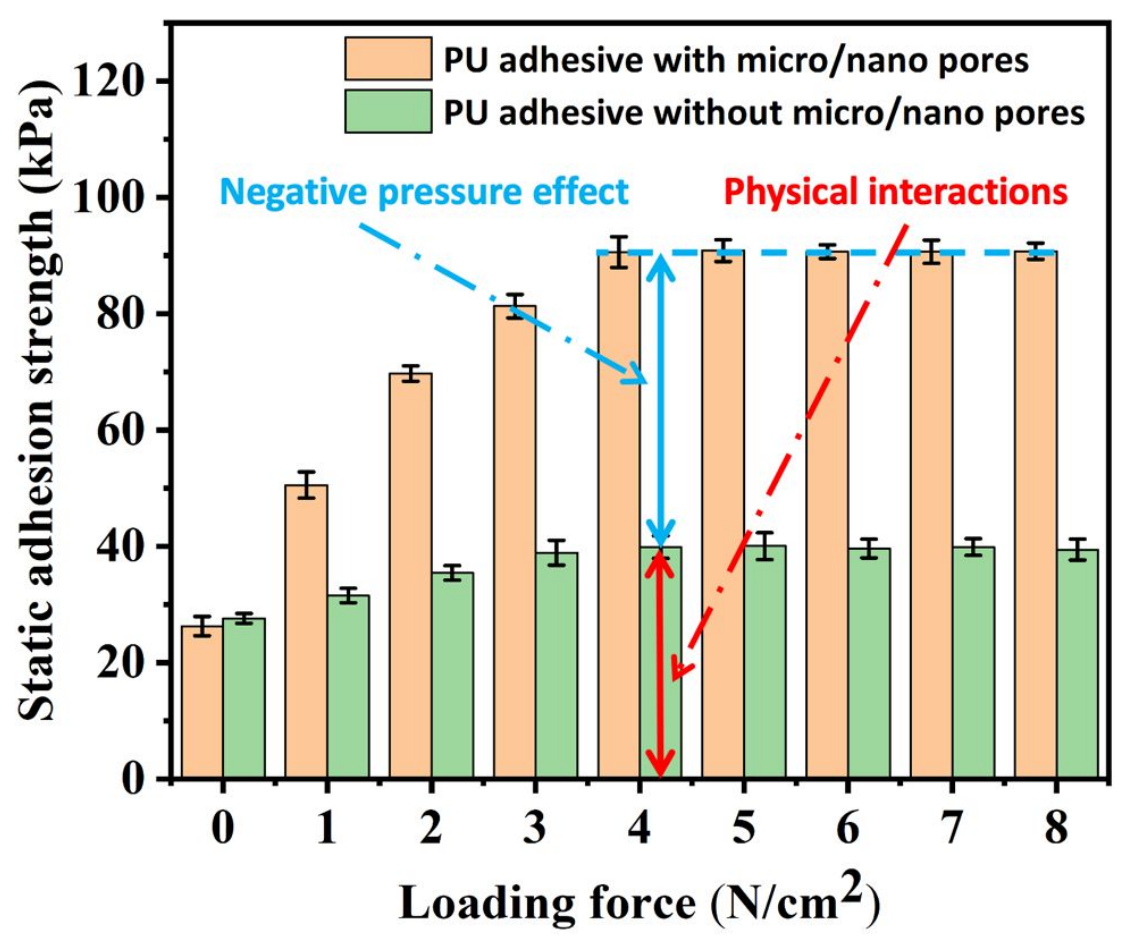

Figure S27. The relationship between the static adhesion performance and loading force of PU adhesive tapes with/without micro/nano pores (on smooth silicon plate). 


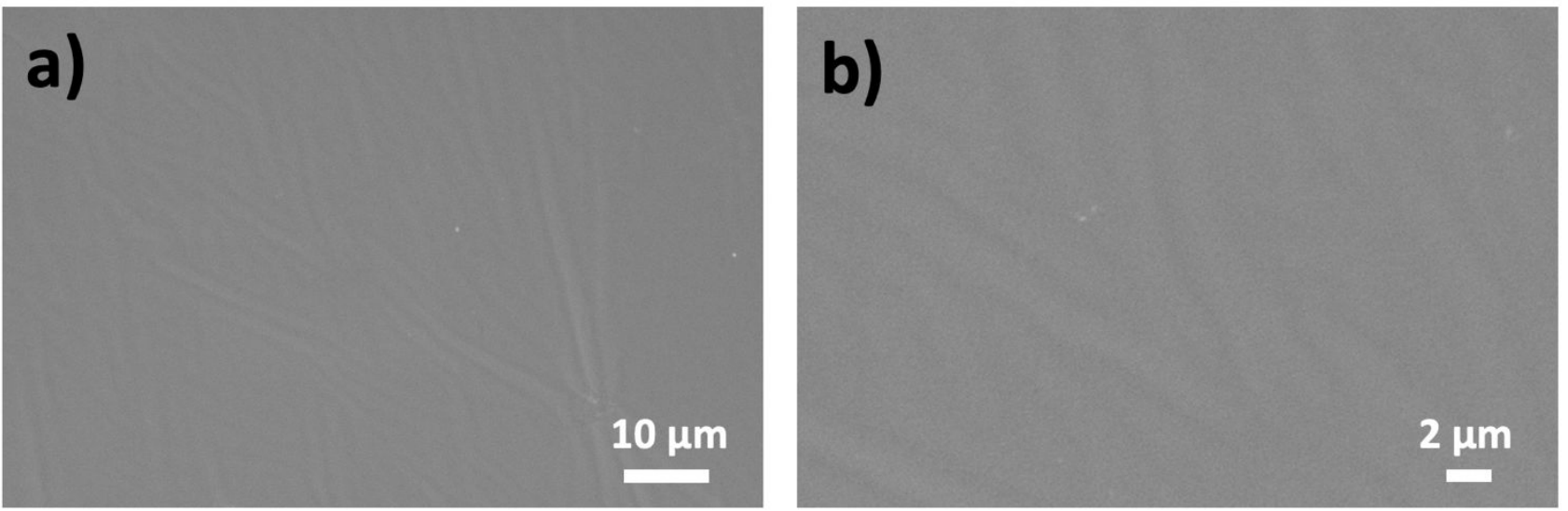

Figure S28. SEM image of the surface structure of the PU adhesive tape without micro/nano pores. 
Original Contact Situation

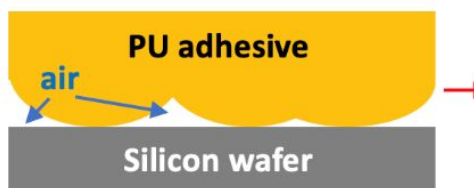

Improving Loading Force

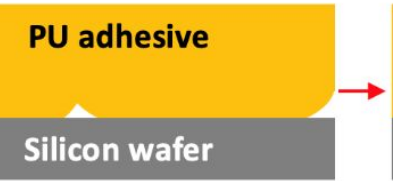

Final Contact Situation

PU adhesive

Silicon wafer

Figure S29. Schematic of showing the evolution of the contact situation of PU adhesive on a flat silicon wafer surface as a function of the joining force. 
Relative Roughness Size
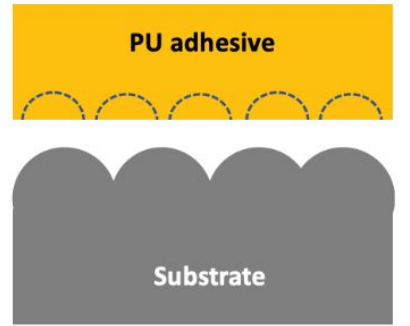

Loading Force
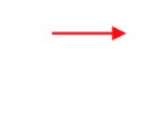

i) size of microstructure larger than micro/nano pores
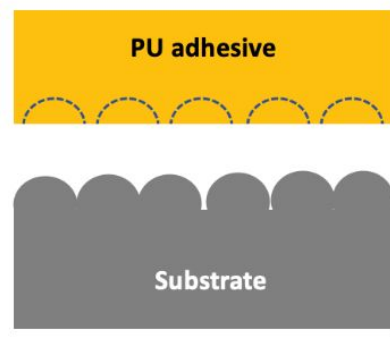

Loading Force
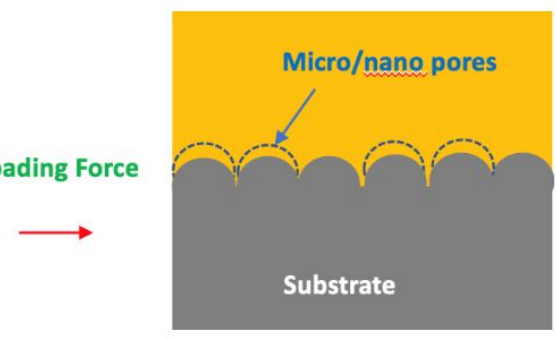

ii) size of microstructure similar to micro/nano pores
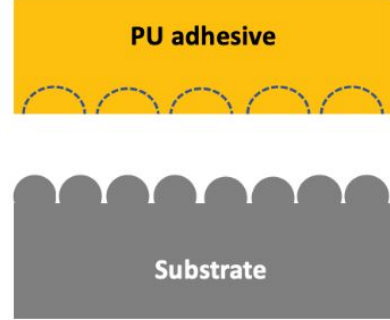

Loading Force

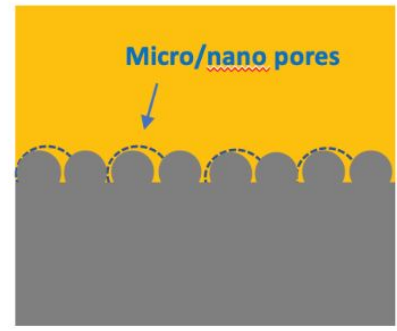

iii) size of microstructure smaller than micro/nano pores

Figure S30. Schematic showing the joining difference between the micro/nano pores and substrates due to the difference of the relative size of surfaces' microstructures.

\section{Supplementary explanation}

If the microstructure of the substrate is larger than the diameter of adhesive' micropores, the air inside the micropores will be discharged and a negative pressure effect will be generated as soon as the micropores contact the substrate. For a substrate with a microstructure similar to the pore size, part of these microstructures will enter the micropores of the adhesive, and would only begin to expel the internal air to produce a negative pressure effect when they cannot enter. If the microstructure of the substrate is smaller than the micropores, the microstructure will enter the micropores entirely before the remaining air is discharged to produce a negative pressure effect. Therefore, compared with substrates with smaller/similar microstructures, the negative pressure effect on the surface with larger-size microstructures is stronger. 

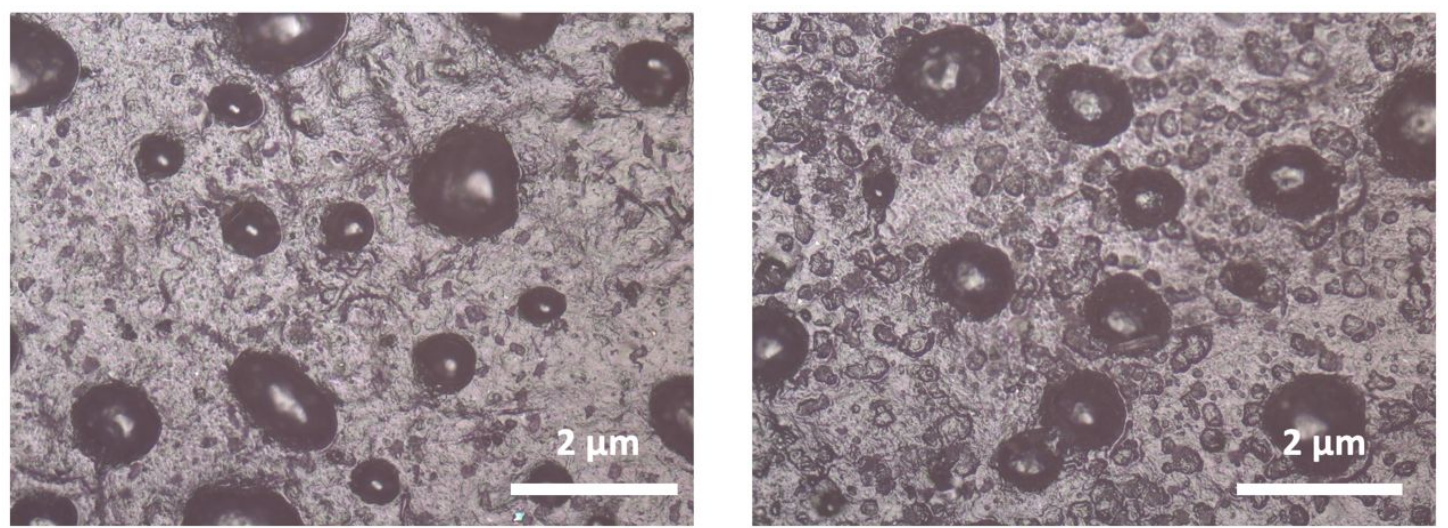

Figure S31. Photographs of the PU adhesive tapes' surface under a high power optical microscope: a) before adhesion. b) after peeling from substrate. 


\section{References:}

1. Davies, J.; Haq, S.; Hawke, T.; Sargent, J., A Practical Approach to the Development of a Synthetic Gecko Tape. Int. J. Adhes. Adhes. 2009, 29 (4), 380-390.

2. Hu, H.; Tian, H.; Li, X.; Shao, J.; Ding, Y.; Liu, H.; An, N., Biomimetic Mushroom-Shaped Microfibers for Dry Adhesives by Electrically Induced Polymer Deformation. ACS Appl. Mater. Interfaces 2014, 6 (16), 14167-14173.

3. Yi, H.; Kang, M.; Kwak, M. K.; Jeong, H. E., Simple and Reliable Fabrication of Bioinspired Mushroom-Shaped Micropillars with Precisely Controlled Tip Geometries. ACS Appl. Mater. Interfaces 2016, 8 (34), 22671-22678.

4. Hu, H.; Tian, H.; Shao, J.; Wang, Y.; Li, X.; Tian, Y.; Ding, Y.; Lu, B., Friction Contribution to Bioinspired Mushroom-Shaped Dry Adhesives. Adv. Mater. Interfaces 2017, 4 (9), 1700016.

5. Murphy, M. P.; Kim, S.; Sitti, M., Enhanced Adhesion by Gecko-Inspired Hierarchical Fibrillar Adhesives. ACS Appl. Mater. Interfaces 2009, 1 (4), 849-855.

6. Rong, Z.; Zhou, Y.; Chen, B.; Robertson, J.; Federle, W.; Hofmann, S.; Steiner, U.; Goldberg-Oppenheimer, P., Bio-Inspired Hierarchical Polymer Fiber-Carbon Nanotube Adhesives. Adv. Mater. 2014, 26 (9), 1456-1461.

7. Bauer, C. T.; Kroner, E.; Fleck, N. A.; Arzt, E., Hierarchical Macroscopic Fibrillar Adhesives: In Situ Study of Buckling and Adhesion Mechanisms on Wavy Substrates. Bioinspir. Biomim. 2015, 10 (6), 066002.

8. Hu, H.; Tian, H.; Shao, J.; Li, X.; Wang, Y.; Wang, Y.; Tian, Y.; Lu, B., Discretely Supported Dry Adhesive Film Inspired by Biological Bending Behavior for Enhanced Performance on a Rough Surface. ACS Appl. Mater. Interfaces 2017, $9(8), 7752-7760$.

9. Wang, Y.; Hu, H.; Shao, J.; Ding, Y., Fabrication of Well-Defined Mushroom-Shaped Structures for Biomimetic Dry Adhesive by Conventional Photolithography and Molding. ACS Appl. Mater. Interfaces 2014, 6 (4), $2213-2218$.

10. Wang, Z., Slanted Functional Gradient Micropillars for Optimal Bioinspired Dry Adhesion. ACS Nano 2018, 12 (2), 1273-1284.

11. Parness, A.; Soto, D.; Esparza, N.; Gravish, N.; Wilkinson, M.; Autumn, K.; Cutkosky, M., A Microfabricated Wedge-Shaped Adhesive Array Displaying Gecko-Like Dynamic Adhesion, Directionality and Long Lifetime. J. R. Soc. Interface 2009, 6 (41), 1223-1232.

12. Tao, D.; Gao, X.; Lu, H.; Liu, Z.; Li, Y.; Tong, H.; Pesika, N.; Meng, Y.; Tian, Y., Controllable Anisotropic Dry Adhesion in Vacuum: Gecko Inspired Wedged Surface Fabricated with Ultraprecision Diamond Cutting. Advanced Functional Materials 2017, 27 (22), 1606576.

13. Jeong, H. E.; Lee, J.-K.; Kim, H. N.; Moon, S. H.; Suh, K. Y., A Nontransferring Dry Adhesive with Hierarchical Polymer Nanohairs. PNAS 2009, 106 (14), 5639-5644.

14. Murphy, M. P.; Aksak, B.; Sitti, M., Gecko-Inspired Directional and Controllable Adhesion. Small 2009, 5 (2), 170 175 .

15. Jin, K.; Cremaldi, J. C.; Erickson, J. S.; Tian, Y.; Israelachvili, J. N.; Pesika, N. S., Biomimetic Bidirectional Switchable Adhesive Inspired by the Gecko. Adv. Funct. Mater. 2014, 24 (5), 574-579.

16. Han, L.; Lu, X.; Liu, K.; Wang, K.; Fang, L.; Weng, L.-T.; Zhang, H.; Tang, Y.; Ren, F.; Zhao, C., Mussel-Inspired Adhesive and Tough Hydrogel Based on Nanoclay Confined Dopamine Polymerization. ACS Nano 2017, 11 (3), $2561-$ 2574.

17. Heinzmann, C.; Weder, C.; de Espinosa, L. M., Supramolecular Polymer Adhesives: Advanced Materials Inspired by Nature. Chem. Soc. Rev. 2016, 45 (2), 342-358.

18. Lu, Q.; Danner, E.; Waite, J. H.; Israelachvili, J. N.; Zeng, H.; Hwang, D. S., Adhesion of Mussel Foot Proteins to Different Substrate. J. R. Soc. Interface 2012, 10 (79), 20120759.

19. Yu, J.; Kan, Y.; Rapp, M.; Danner, E.; Wei, W.; Das, S.; Miller, D. R.; Chen, Y.; Waite, J. H.; Israelachvili, J. N., Adaptive Hydrophobic and Hydrophilic Interactions of Mussel Foot Proteins with Organic Thin Films. Proc. Natl. Acad. 
Sci. U.S.A. 2013, $110(39), 15680-15685$.

20. Lu, Q.; Oh, D. X.; Lee, Y.; Jho, Y.; Hwang, D. S.; Zeng, H., Nanomechanics of Cation- $\pi$ Interactions in Aqueous Solution. Angew. Chem. Int. Ed. 2013, 125 (14), 4036-4040. 